\title{
Recent Changes in Surface Humidity: Development of the HadCRUH Dataset
}

\author{
KATHARINE M. WiLLETT \\ Climatic Research Unit, School of Environmental Sciences, University of East Anglia, Norwich, and Met Office Hadley Centre, \\ Exeter, United Kingdom, and Geology and Geophysics Department, Yale University, New Haven, Connecticut \\ Philip D. Jones AND Nathan P. Gillett \\ Climatic Research Unit, School of Environmental Sciences, University of East Anglia, Norwich, United Kingdom \\ Peter W. Thorne \\ Met Office Hadley Centre, Exeter, United Kingdom
}

(Manuscript received 9 October 2007, in final form 14 March 2008)

\begin{abstract}
Water vapor constitutes the most significant greenhouse gas, is a key driver of many atmospheric processes, and hence, is fundamental to understanding the climate system. It is a major factor in human "heat stress," whereby increasing humidity reduces the ability to stay cool. Until now no truly global homogenized surface humidity dataset has existed with which to assess recent changes. The Met Office Hadley Centre and Climatic Research Unit Global Surface Humidity dataset (HadCRUH), described herein, provides a homogenized quality controlled near-global $5^{\circ}$ by $5^{\circ}$ gridded monthly mean anomaly dataset in surface specific and relative humidity from 1973 to 2003 . It consists of land and marine data, and is geographically quasicomplete over the region $60^{\circ} \mathrm{N}-40^{\circ} \mathrm{S}$.

Between 1973 and 2003 surface specific humidity has increased significantly over the globe, tropics, and Northern Hemisphere. Global trends are 0.11 and $0.07 \mathrm{~g} \mathrm{~kg}^{-1}(10 \mathrm{yr})^{-1}$ for land and marine components, respectively. Trends are consistently larger in the tropics and in the Northern Hemisphere during summer, as expected: warmer regions exhibit larger increases in specific humidity for a given temperature change under conditions of constant relative humidity, based on the Clausius-Clapeyron equation. Relative humidity trends are not significant when averaged over the landmass of the globe, tropics, and Northern Hemisphere, although some seasonal changes are significant.

A strong positive bias is apparent in marine humidity data prior to 1982, likely owing to a known change in reporting practice for dewpoint temperature at this time. Consequently, trends in both specific and relative humidity are likely underestimated over the oceans.
\end{abstract}

\section{Introduction}

Changes in atmospheric humidity are key to understanding the dynamical and radiative aspects of climate change (Manabe and Wetherald 1967; Kiehl and Trenberth 1997; Held and Soden 2000). They are also fundamental in quantifying changes in the atmospheric heat content (Davey et al. 2006): temperature alone is insufficient. The Clausius-Clapeyron relation describes

Corresponding author address: Katharine M. Willett, Met Office Hadley Centre, Fitzroy Road, Exeter, EX1 3PB, United Kingdom.

E-mail: kate.willett@metoffice.gov.uk the exponential increase of the water holding capacity of the atmosphere with increasing temperature $(T)$ such that for a $1-\mathrm{K}$ increase in $T$, surface saturated specific humidity $\left(q_{s}\right)$ or saturated vapor pressure $\left(e_{s}\right)$ should increase approximately $7 \%$, increasing with latitude and altitude (Sun and Held 1996; Held and Soden 2006). It has often been suggested that relative humidity $(\mathrm{RH})$ should remain quasi-constant under conditions of climate change (Arrhenius 1896; Manabe and Wetherald 1975) and, indeed, this has been an emergent property of general circulation models (GCMs) of the climate system (Held and Soden 2000; Allen and Ingram 2002; Ingram 2002). Therefore it may be expected that the actual amount of moisture held in the 
TABLE 1. A summary of previous humidity studies.

\begin{tabular}{|c|c|c|c|c|c|}
\hline Study & Region & Period & Trends and variables & $\begin{array}{l}\text { Quality } \\
\text { control } \\
\text { applied }\end{array}$ & $\begin{array}{l}\text { Long-term } \\
\text { homogeneity } \\
\text { assessments }\end{array}$ \\
\hline $\begin{array}{l}\text { Gaffen and Ross } \\
\text { (1999) }\end{array}$ & United States & $1961-95$ & $\begin{array}{l}\text { Significant moistening }\left(q, e, \text { and } T_{d}\right) \\
\text { over most regions/seasons } \\
\text { Some relative moistening }(\mathrm{RH}), \text { at } \\
\text { night, during winter but lacking } \\
\text { significance and spatial consistency }\end{array}$ & Yes & Yes \\
\hline Robinson (2000) & United States & 1951-92 & $\begin{array}{l}\text { Moistening }\left(T_{d}\right) \text { over most } \\
\text { regions/seasons }\end{array}$ & Yes & Yes \\
\hline $\begin{array}{l}\text { Van Wijngaarden } \\
\text { and Vincent (2005) }\end{array}$ & Canada & $1953-2003$ & $\begin{array}{l}\text { Significant RH trends found of } \\
\text { either sign }\end{array}$ & Yes & Yes \\
\hline Vincent et al. (2007) & Canada & 1953-2005 & $\begin{array}{l}\text { Significant moistening }(q, \mathrm{Td}) \\
\text { especially at night } \\
\text { Lower RH in winter and spring }\end{array}$ & Yes & Yes \\
\hline Kaiser (2000) & China & 1954-96 & $\begin{array}{l}\text { Significant moistening }(e) \text { over most } \\
\text { regions/seasons } \\
\text { Significant RH trends found of } \\
\text { either sign }\end{array}$ & No & Yes \\
\hline $\begin{array}{l}\text { Wang and Gaffen } \\
\text { (2001) }\end{array}$ & China & $1951-94$ & $\begin{array}{l}\text { Significant moistening }(e) \text { over most } \\
\text { regions/seasons } \\
\text { Significant } \mathrm{RH} \text { trends found of } \\
\text { either sign }\end{array}$ & Yes & Yes \\
\hline $\begin{array}{l}\text { Schönwiese et al. } \\
\text { (1994); Schönwiese } \\
\text { and Rapp (1997) }\end{array}$ & $\begin{array}{l}\text { Europe }\left(35^{\circ}-72^{\circ} \mathrm{N},\right. \\
\left.15^{\circ} \mathrm{W}-50^{\circ} \mathrm{E}\right)\end{array}$ & 1961-90 & Significant moistening in $e$ & Yes & No \\
\hline New et al. (2000) & Global (land only) & $1975-95$ & $\begin{array}{l}\text { Nominally significant moistening }(e) \text { is } \\
\text { widespread with patches of drying }\end{array}$ & Yes & No \\
\hline Dai (2006) & $\begin{array}{l}\text { Global (land and } \\
\text { marine) }\end{array}$ & $1975-2005$ & $\begin{array}{l}\text { Significant global moistening }(q) \text { of } \\
0.06 \mathrm{~g} \mathrm{~kg}^{-1}(10 \mathrm{yr})^{-1} \\
\text { Significant relative }(\mathrm{RH}) \text { drying } \\
\text { globally at }-0.09 \%(10 \mathrm{yr})^{-1}\end{array}$ & Yes & No \\
\hline Ishii et al. (2005) & Global (marine only) & 1901-2001 & Moistening in $T_{d}$ & Yes & Yes \\
\hline Worley et al. (2005) & Global (marine only) & $1800-2005$ & No trends analyzed & Yes & No \\
\hline
\end{tabular}

atmosphere [the specific humidity $(q)$ and vapor pressure $(e)$ ] will increase with increasing $T$. The question is, does this hold true in the real world and, if so, over what spatial and temporal scales?

Monitoring of changes in surface humidity, as a source of water vapor throughout the troposphere, is an essential first step to documenting and understanding changes aloft. Such understanding has implications for a number of important issues: quantifying climate sensitivity due to the positive water vapor feedback mechanism (Held and Soden 2000); the formation of and radiative interplay with clouds which are the main source of uncertainty in GCMs (Trenberth et al. 2005; Webb et al. 2006); the earth's energy budget in terms of additional latent heat release in the free troposphere, with potential implications for hurricane formation and intensity (Trenberth 2005; Anthes et al. 2006); and intensification of the hydrological cycle (Trenberth 1999a,b; Pall et al. 2007; Wentz et al. 2007; Zhang et al. 2007). Quantifying if and how changes in surface RH have occurred may help clarify recent debate over an appar- ent disparity between upper-tropospheric water vapor in models and observations (Zhang and Sun 2006).

In addition to improving our understanding of the climate system as a whole, quantifying changes in surface humidity across the globe enables further and more detailed diagnosis of climate change. Based on the Clausius-Clapeyron relationship the strongest moistening signals are likely to occur in warmer regions, particularly those where there is a substantial surface moisture source. Humidity has relevance for climate impact studies including human heat stress, whereby an increase in humidity compromises the body's ability to keep cool through evaporation of perspiration (Steadman 1984; Souch and Grimmond 2004). There is much potential for combining historical humidity, temperature, and epidemiological records with forecast capabilities to provide improved human health warnings and hospital demand forecasts, over time scales from days to decades.

There are a number of previous surface humidity studies of note (summarized in Table 1), all generally 
converging on a picture of absolute moistening. These studies have either been regional in focus, or lacking in efforts to homogenize the data in a meaningful manner. Rigorous attempts to homogenize the data are necessary to ensure data quality and enhance signal detection (Easterling and Peterson 1995; Jones et al. 1999; Vincent et al. 2002).

This paper describes the creation of the Met Office Hadley Centre and Climatic Research Unit Global Surface Humidity Dataset (HadCRUH); now freely available for download at http://www.hadobs.org)—the first rigorously homogenized and quality controlled global gridded $\left(5^{\circ}\right.$ by $\left.5^{\circ}\right)$ monthly mean anomaly humidity dataset in $q$ and $\mathrm{RH}$ suitable for use in climate studies. Section 2 describes the conversion algorithms chosen. Section 3 focuses on construction of the land component. Section 4 details the marine component. An analysis of the data is given in section 5 , and a summary in section 6 .

\section{Choosing suitable humidity variable and conversion algorithms}

Although atmospheric humidity can be measured in several ways, measurements from the databases used here (described below) are recorded as dewpoint temperature $\left(T_{d}\right)$, the temperature to which the air must be cooled for the water vapor in it to begin to condense. We require specific humidity $(q)$ and relative humidity $(\mathrm{RH})$, and therefore must convert to these variables. There are a wide number of humidity variables and conversion algorithms. Conversions from $T$ and $T_{d}$ are nonlinear and each algorithm varies in complexity and error (none are error free). Here, algorithms have been chosen balancing between perceived accuracy and ease of implementation over large datasets. We use only the stations and times at which simultaneous $T$ and $T_{d}\left({ }^{\circ} \mathrm{C}\right)$ were recorded, and $T_{d}$ is converted first to vapor pressure (e) based on an equation from Buck (1981):

$$
\begin{aligned}
e_{w} & =6.1121 f_{w} \exp \left\{\frac{\left[18.729-\left(T_{d} / 227.3\right)\right] T_{d}}{257.87+T_{d}}\right\}, \\
f_{w} & =1+7 \times 10^{-4}+\left(3.46 \times 10^{-6} P\right), \\
e_{i} & =6.1121 f_{i} \exp \left\{\frac{\left[23.036-\left(T_{d} / 333.7\right)\right] T_{d}}{279.82+T_{d}}\right\}, \\
f_{i} & =1+3 \times 10^{-4}+\left(4.18 \times 10^{-6} P\right),
\end{aligned}
$$

where $e_{w}(\mathrm{hPa})$ refers to vapor pressure with respect to a wet bulb $\left(T_{w}>0{ }^{\circ} \mathrm{C}\right.$, where $T_{w}$ is wet-bulb temperature), $e_{i}(\mathrm{hPa})$ refers to vapor pressure with respect to an ice bulb $\left(T_{w} \leq 0^{\circ} \mathrm{C}\right)$, and $P$ is atmospheric pressure (in $\mathrm{hPa}$ ). This equation has been chosen over the more

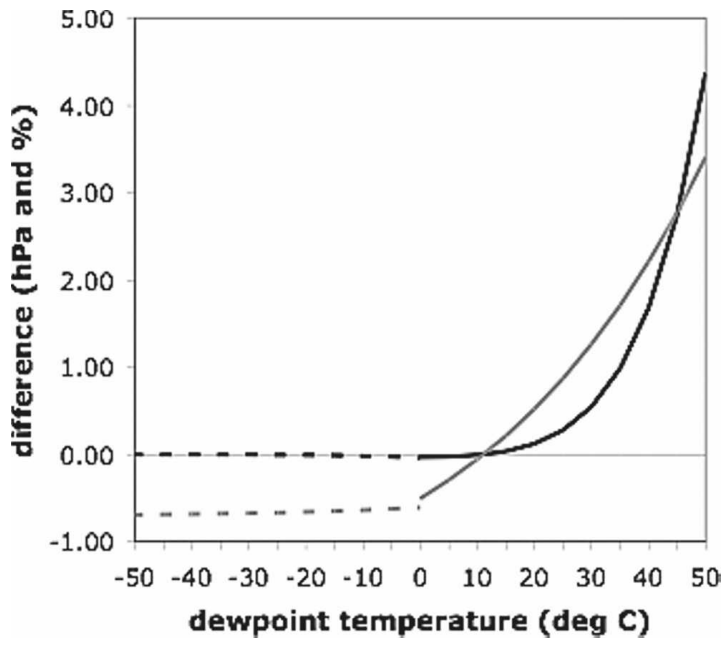

FIG. 1. Difference in $e$ calculated using the Goff and Gratch (1946) (for $<0^{\circ} \mathrm{C}$ ) and Goff (1957) (for $>0^{\circ} \mathrm{C}$ ) formulas verses that of Buck (1981) [hPa (black) and \% (gray)]. Dashed and solid lines show $e$ calculated with respect to ice and water, respectively.

conventional Goff-Gratch formulas (Goff and Gratch 1946; Goff 1957) because it is less complex and therefore easier to manipulate later in terms of converting between variables. The difference between $e$ both in actual and percentage terms is small at less than $1 \mathrm{hPa}$ and approximately $1.5 \%$, respectively, for $T_{d}$ below $30^{\circ} \mathrm{C}$ (Fig. 1). These differences increase with increasing $T_{d}$.

Although wet-bulb temperature $\left(T_{w}\right)$ is similar to $T_{d}$, it is not the same; therefore, we also need $T_{w}$ to determine whether to calculate relative to water or ice. In the marine data $T_{w}$ is sometimes present and used if it passes all quality control tests. Otherwise, and for the land data, $T_{w}$ (in ${ }^{\circ} \mathrm{C}$ ) is calculated using an equation from Jensen et al. (1990):

$$
T_{w}=\left[\frac{(a T)+\left(b T_{a}\right)}{a+b}\right],
$$

in which

$$
a=0.000066 P \text { and } \quad b=\left[\frac{409.8 e}{\left(T_{d}+237.3\right)^{2}}\right],
$$

where $e$ is calculated as for $e_{w}$ [Eq. (1a)]. This creates a problem whereby $T_{w}$ is required to determine whether to calculate $e$ with respect to water or ice, but first $e$ is required to calculate $T_{w}$. For this purpose, $e$ is always calculated with respect to water regardless. In cases where $e_{i}$ is required, $T_{w}$ is underestimated such that for a very narrow range of meteorological conditions $e$ will be undervalued [i.e., for a $\mathrm{RH}$ of $70 \%(40 \%)$ and a simultaneous $T_{d}$ between $-3.1^{\circ}$ and $-3.2^{\circ} \mathrm{C}\left(-9.0^{\circ}\right.$ and 
$\left.-9.3^{\circ} \mathrm{C}\right)$ there is a potential error of $\left.-3.1 \%(-8.4 \%)\right]$. Given that input values are to one decimal place, only low humidity conditions where $T$ and $T_{d}$ straddle $0^{\circ} \mathrm{C}$ are of concern. Any errors incurred should have minimal effect on a final monthly mean anomaly product.

Equations (3) (Peixoto and Oort 1996) and (4) are used to calculate $q\left(\mathrm{~g} \mathrm{~kg}^{-1}\right)$ and $\mathrm{RH}(\%)$ respectively:

$$
q=1000\left\{\frac{\varepsilon e}{P-[(1-\varepsilon) e]}\right\}
$$

in which $\varepsilon=0.622$, and

$$
\mathrm{RH}=100\left(\frac{e}{e_{s}}\right),
$$

where $e_{s}$ is the saturated vapor pressure (hPa) and is calculated by substituting $T_{d}$ with $T$ in the equation for $e$ [Eqs. (1a) and (1b)]. For the marine data a standard $P$ $(1013 \mathrm{hPa})$ is used. For the land data $P$ is calculated using station elevation:

$$
P=1013-\left(\frac{Z_{s}}{10}\right)
$$

where $Z_{s}(\mathrm{~m})$ is the station elevation. The choice of calculating $P$ in this way as opposed to using simultaneous or climatological $P$ is made based on balancing ease of use for a large first version dataset and small potential errors. These potential errors are negligible when calculating $e$ and small for $q$, on the order of $-0.1 \%$ per $1-\mathrm{hPa}$ increase in $P$ (Willett 2007). As recorded trends in surface $P$ for the period from 1973 to 2003 [from the Hadley Centre's Mean Sea Level Pressure Dataset (HadSLP2) (Allan and Ansell 2006)] are generally $<1 \mathrm{hPa}(10 \mathrm{yr})^{-1}$, this assumption of constant pressure should add negligible error in the long-term trend estimates.

\section{The land component}

Version 2 of the Integrated Surface Dataset (ISD), supplied by the National Climatic Data Center (NCDC) (Lott et al. 2001) forms the basis of the land dataset. It reports $T$ and $T_{d}$ with subhourly (better than hourly) to daily frequency. The data have already undergone a rigorous (but not exhaustive) quality control (Lott et al. 2001). All data flagged as "good" quality by ISD are converted to $e, q$, and $\mathrm{RH}$, and then subhourly data are averaged to hourly for computational convenience by assigning to the nearest whole hour. Initially, it was intended to produce HadCRUH in $e, q$, and $\mathrm{RH}$, so much of the quality control process considers $e$. However, it became apparent that $q$ and $\mathrm{RH}$ are at present of most use and relevance to the scientific com- munity and so the final dataset consists solely of these variables.

The ISD database provides good coverage both spatially and temporally, especially in the Northern Hemisphere, from 1973 onward. Thus HadCRUH begins in 1973 and, for the purpose of this study, ends in 2003. However, since ISD is updated yearly, there is scope for updating HadCRUH in near-real time in the future in addition to improving spatial coverage.

Use of a standard WMO reference period (i.e., from 1961 to 1990), although consistent with numerous other key climate datasets [e.g., the second Met Office Hadley Centre Sea Surface Temperature Dataset (HadSST2) — Rayner et al. (2006); HadSLP_Allan and Ansell (2006); the third Met Office Hadley Centre and Climatic Research Unit Global Land and Sea Surface Temperature Dataset (HadCRUT3)—Brohan et al. (2006)], would drastically compromise station density and breadth of coverage in HadCRUH. Station coverage is maximized by using a 1974-2003 climatology. To be included, a station must conform to the following minimum criteria (based loosely on Jones and Moberg 2003): four reporting times with data per day covering both halves of the diurnal cycle (midnight to midday, midday to midnight); $75 \%$ of days with data per month; two months with data per season; three seasons with data per year; five years with data per decade; two decades with data; and 15 years within the climatology period.

The resulting spatial coverage is near global and very good over Europe and Southeast Asia but surprisingly poor over the United States (Fig. 2a). There are numerous stations throughout the United States, but the temporal longevity of many records within ISD is insufficient to create a climatology for most of these sites. Efforts to combine station records reporting under different identification (ID) numbers for different time periods for all stations improved coverage slightly. Given the density of the U.S. Historical Climatology Network (USHCN) (Easterling et al. 1999) and other networks, it is clear that further data exist to augment this in the future.

There are two principal aspects to the creation of a homogeneous humidity dataset. First, there is the removal of bad or clearly erroneous data and, second, the assessment of the long-term homogeneity of the remaining station humidity records. To assess the former, further quality control in addition to that already undertaken by NCDC was deemed necessary including a number of tests specific to humidity. A number of issues are investigated (Table 2) using a subset of "good" quality (at least six hourly observing frequency with a long period of record) case study stations (Willett 

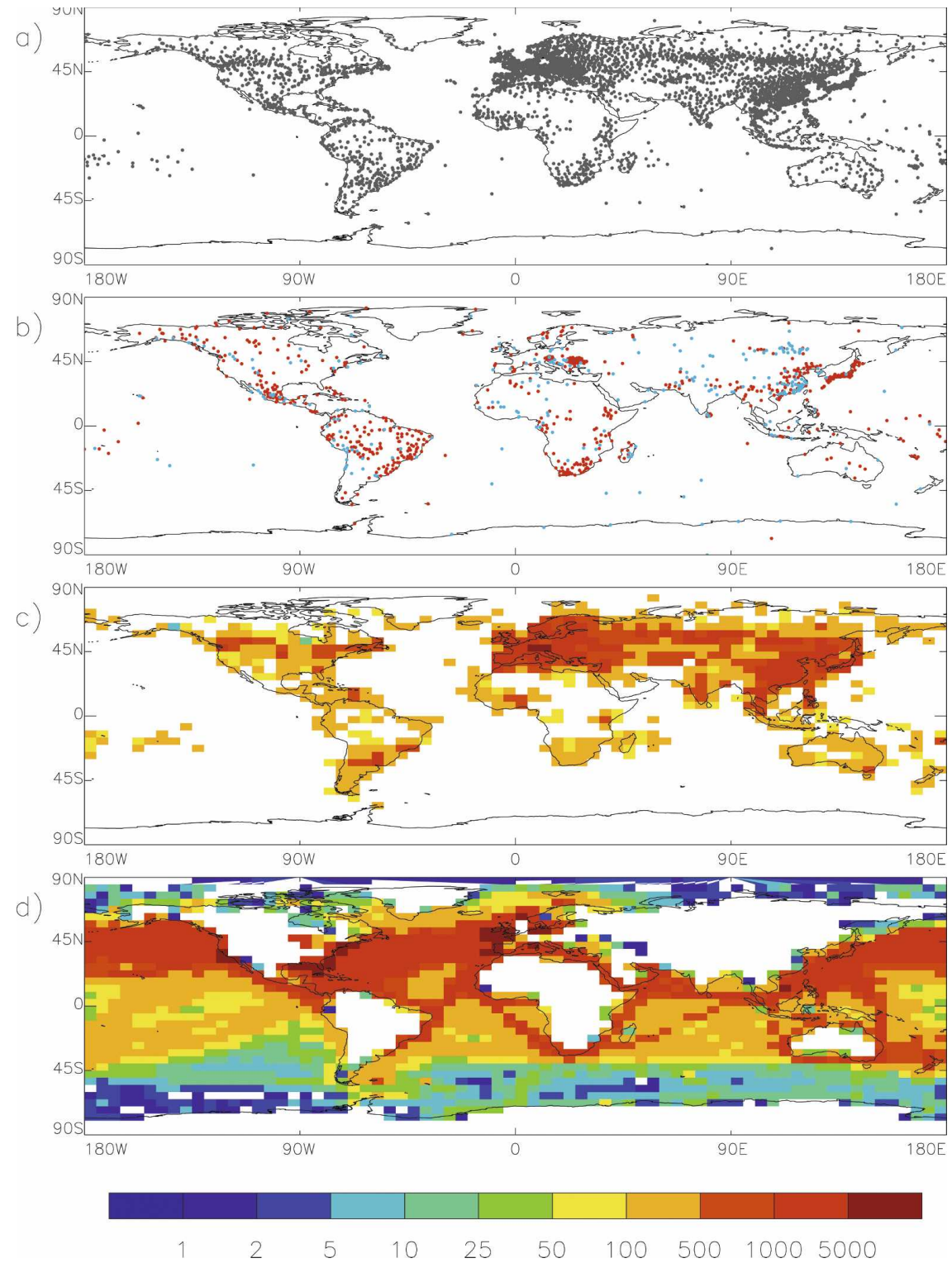

FIG. 2. HadCRUH data coverage: (a) spatial coverage of all ISD land stations providing sufficient data to create a 1974-2003 climatology (4760 stations); (b) stations removed by the quality control (red) and homogenization (blue) processes (1517 stations); (c) average monthly gridbox observation density for the quality controlled and homogenized land data (assuming 4 observations per day and 30 days per month, i.e., 120 per station month); and (d) average monthly gridbox observation density for the quality controlled and homogeneity checked marine data.

2007). A set of five tests result to identify physically implausible values, repeated values, wick drying, reservoir freezing and icing events affecting the wet-bulb thermometer, cutoffs of humidity observations in extremes, and outliers. Respective data removal amounts are shown in Table 2 and geographically in Fig. 2 b. The development and rationale for these tests is described in detail in Willett (2007). These tests largely focus on
$T$ and $T_{d}$ and then $e$ as a representative humidity variable (for identifying repeats and outliers). It is not necessary to apply quality control to all variables separately based on the assumption that issues of quality arising in either the source variables $\left(T\right.$ and $T_{d}$ ) or in one humidity variable will pertain to all other humidity variables converted from the same source. On completion of the quality control, stations with sufficient data 
TABLE 2. Quality control tests for the land data and data removal summary as a percentage of all data. Total data removal resulting from the quality control is greater than shown here owing to some stations no longer having sufficient data with which to calculate a climatology.

\begin{tabular}{|c|c|c|}
\hline Test & Description & Data removed \\
\hline Bad values & $\begin{array}{l}\left.\text { Physically unrealistic values are removed [i.e., } T_{d}>T ; T \text { (or } T_{d}\right)<-80^{\circ} \mathrm{C} \text { or } \\
\left.>60^{\circ} \mathrm{C} ; \mathrm{RH}(\text { or } e)<0 \%(\text { or } \mathrm{hPa})\right] \text {. }\end{array}$ & $0.004 \%$ \\
\hline Repeated values & $\begin{array}{l}\text { Considering the diurnal cycle, } T \text { values that persist for more than } 12 \mathrm{~h} \text { are } \\
\text { considered erroneous and the entire string bar the first value is removed. }\end{array}$ & $0.42 \%$ \\
\hline $\begin{array}{l}\text { Persistent } 0^{\circ} \mathrm{C} \text { dewpoint } \\
\text { depression (DPD) }\end{array}$ & $\begin{array}{l}\text { Wet-bulb thermometers are highly susceptible to reservoir freezing or drying } \\
\text { out and screen freezing, all of which inhibit evaporation giving identical } T_{w} \\
\text { and } T \text { readings }\left(0^{\circ} \mathrm{C} \mathrm{DPD}\right) \text {. Periods of persistent }(>12 \mathrm{~h}) 0^{\circ} \mathrm{C} \text { DPD are be- } \\
\text { lieved to indicate such episodes and so the entire string is removed. }\end{array}$ & $1.25 \%$ \\
\hline Cutoffs & $\begin{array}{l}\text { In temperature extremes, } T_{d} \text { is not always reported (historically the case for } \\
\text { radiosonde data; Elliott } 1995 \text { ). Data are checked (in bins of } 10^{\circ} \mathrm{C} \text { ) for simul- } \\
\text { taneous } T \text { and } T_{d} \text { reporting. Years where missing } T_{d} \text { values exceed } 10 \% \text { of } \\
\text { the total are removed. }\end{array}$ & $4.07 \%$ \\
\hline Outliers & $\begin{array}{l}\text { Data points (in } e \text { ) greater than three std dev from the mean [in addition to } \\
\text { other criteria utilizing the first difference series and missing data points to } \\
\text { take into account adjacent (in time) values (Willett 2007)] are removed. }\end{array}$ & $0.17 \%$ \\
\hline & Other issues considered but not implemented & \\
\hline $\begin{array}{l}\text { Poor ventilation- } \\
\text { low wind speeds }\end{array}$ & $\begin{array}{l}\text { Some wet-bulb thermometers depend on natural aeration to enable evapora- } \\
\text { tion to occur. In very low wind speeds this may be a problem. } \\
\text { It was not possible to identify any stations where such measurement errors } \\
\text { were apparent or quantify the extent of this problem within the land data. } \\
\text { Availability of simultaneous wind data was intermittent, and instrument } \\
\text { type metadata were entirely lacking. }\end{array}$ & - \\
\hline Reporting time zones & $\begin{array}{l}\text { It is possible that observation times are recorded incorrectly or that not all } \\
\text { ISD data are (as documented) converted to UTC. } \\
\text { All case study stations were converted to UTC correctly. There was some in- } \\
\text { consistency in the diurnal cycle of some stations but efforts to automate a } \\
\text { "detection and removal" program were unsuccessful. The use of anomalies } \\
\text { should minimize any impact of such errors and any related long-term } \\
\text { changes should be identified during homogenization. }\end{array}$ & - \\
\hline Elevation & $\begin{array}{l}\text { The effect of elevation on spatial continuity in humidity is complex and rela- } \\
\text { tively unstudied. } \\
\text { Stations were found to correlate well over large distances and elevations ex- } \\
\text { cept when slope aspect differed, a likely scenario within a } 5^{\circ} \text { by } 5^{\circ} \text { grid box. } \\
\text { Removing stations in data-sparse areas was undesirable. No clear and } \\
\text { simple way to address this problem was found and so all stations were kept } \\
\text { regardless of elevation. }\end{array}$ & - \\
\hline
\end{tabular}

remaining are transformed to pentad (5-day mean, see appendix A) anomalies. Pentads are preferred at this stage to daily or monthly both for computational convenience (especially homogenization) and for the later possibility of producing a higher-resolution dataset. The ocean data is also available at pentad resolution, so for compatibility of the two sources this is optimal.

The size of the land dataset necessitates a largely automated approach to homogenization but with manual input required for breakpoint identification. The technique is modified from that used in the creation of the Hadley Centre Radiosonde Temperature Dataset (HadAT) (Thorne et al. 2005) and applied to the pentad anomaly $q$ dataset (appendix A). As $q$ is relatively spatially consistent over hundreds of kilome- ters (Willett 2007), any observed spikes in humidity seen at one station can be expected to appear in a sufficiently correlating, but independent, background field. Neighbor composites (appendix B) are used to create an independent background expectation field and a difference series is calculated. This allows for further and more sensitive outlier checking where any pentad in the difference series greater than four standard deviations from the mean is removed from the target station record.

Breakpoints in the difference series (candidate minus background expectation series) are identified using a Kolmogorov-Smirnov (K-S) test (Press et al. 1992) on two years of difference series data either side of each pentad (temporal coverage is matched for missing data 
a)
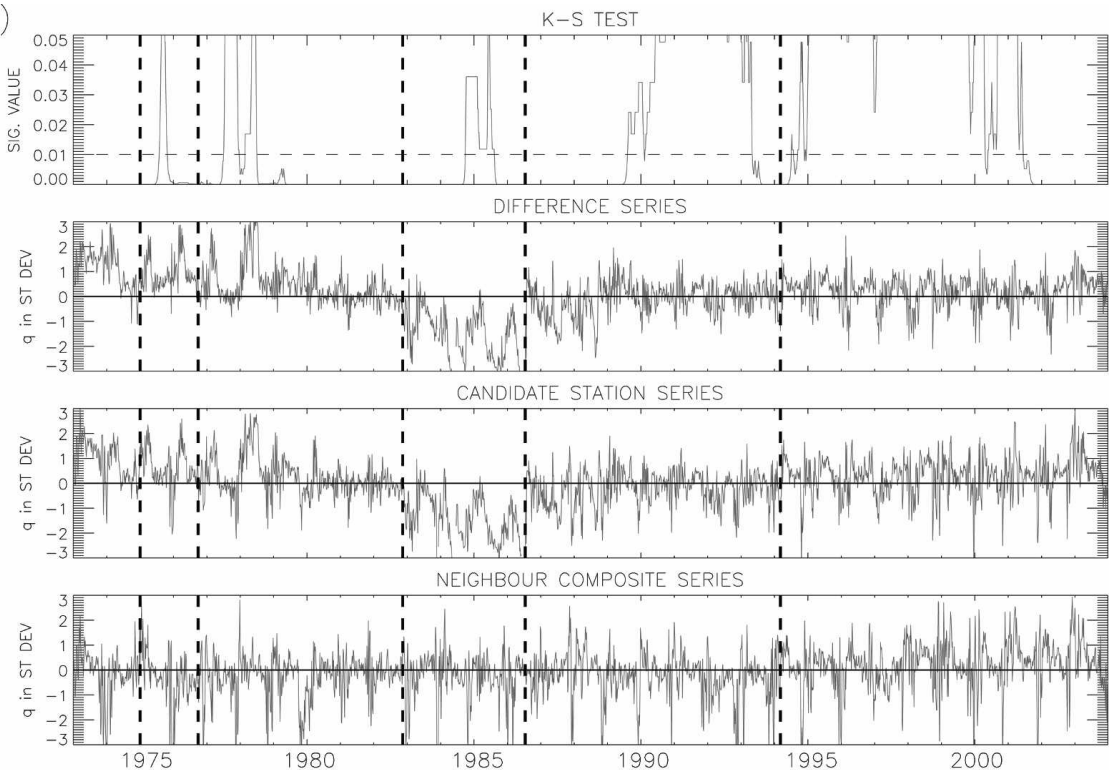

b)

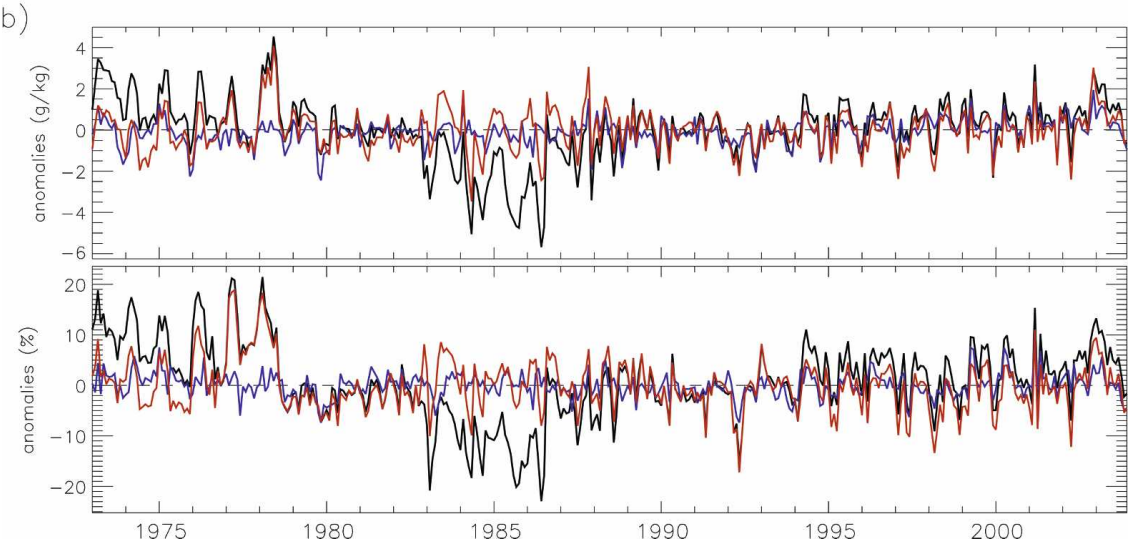

FIG. 3. Example of the land homogenization process for station 483270 (Chiang Mai, Thailand): (a) panel for manual analysis to reject/accept breakpoints and (b) comparison of monthly mean anomaly $q$ (top) and RH (bottom) before (black) and after (red) homogenization and the neighbor composite time series (blue). For (a) vertical dashed lines represent potential breakpoints, all five are accepted in this case and adjustments made. No adjustment is made for the 1978 period where candidate and neighbor composite differ noticeably. This is because in the pentad time series [shown in (a)] this deviation from the neighbor composite series is not persistent enough to sustain a $\mathrm{K}-\mathrm{S}$ test score significant at $0.01 \%$ continuously for more than 36 pentads.

to avoid any seasonal bias) where at least one-third of data are present. Strings of pentads where the K-S test gives at least $0.01 \%$ significance consecutively for at least six months thereafter are potential periods of inhomogeneity. The pentad with the lowest K-S test significance in each such continuous string is marked as a potential breakpoint. Potential breakpoints are manually accepted or rejected based on interpretation of the $\mathrm{K}-\mathrm{S}$ test value-approximate means either side of the breakpoint and whether the discontinuity genuinely ap- pears to originate from the candidate and not the neighbor-based expectation series. An example homogenization panel for manual scrutiny is shown here in Fig. 3a. Adjustments are made by adding the difference in medians of the difference series before and after the breakpoint to all prebreakpoint data. The data are then adjusted to give a mean of zero over the climatology period. Stations with many, or very complex, discontinuities and/or long gaps in the record compromise the value of any adjustments made and are subjectively re- 

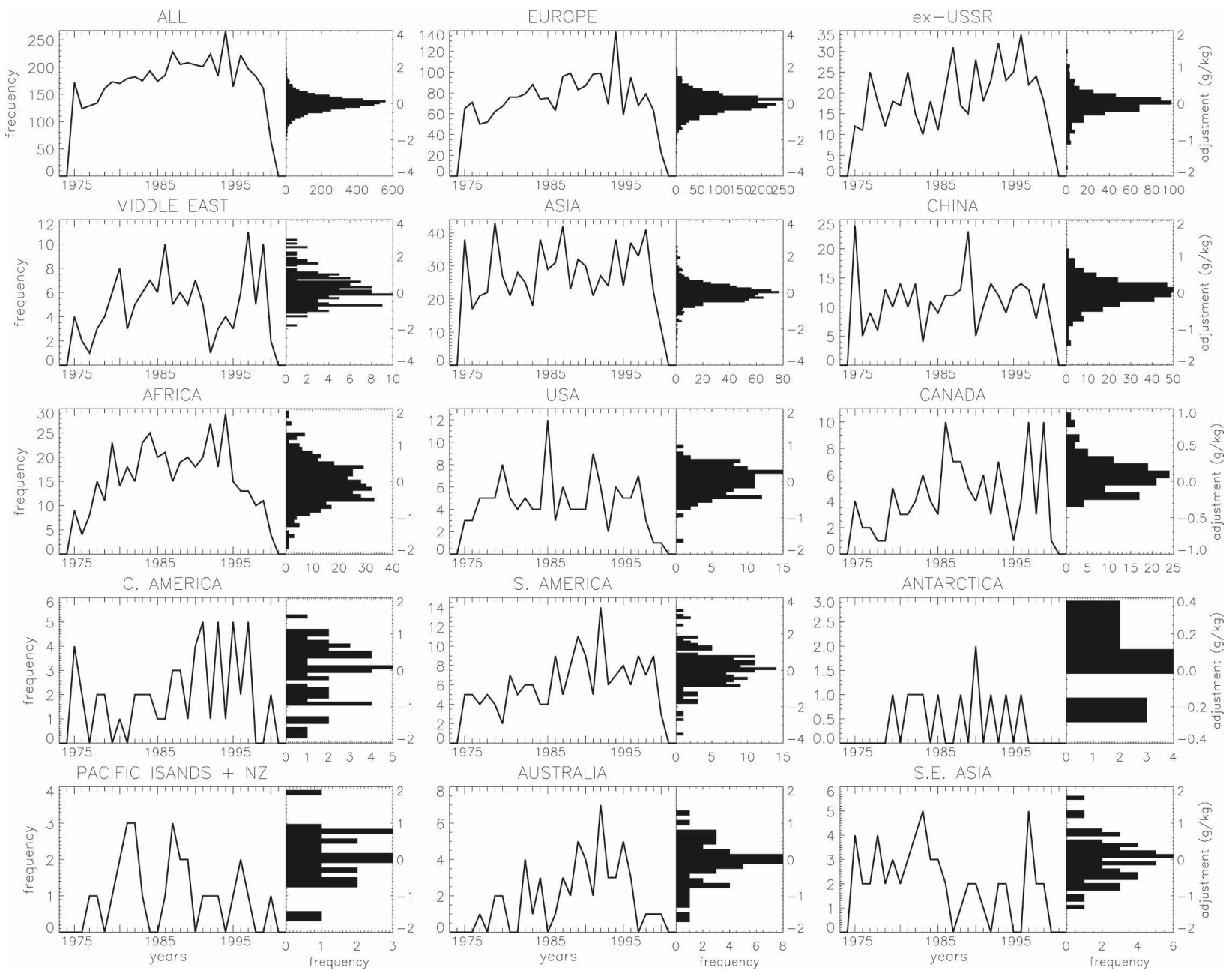

FIG. 4. Frequency distribution of accepted breakpoints over time (left-hand side of each panel) and adjustment quantities (right-hand side of each panel) made in the first iteration of the land homogenization process for all stations by region.

moved from the dataset (Fig. 2b). The homogenization process is reiterated until the number of adjustments applied falls below $25 \%$ of that made in the first iteration. For RH, correlation regions, neighbor composites and adjustment quantities are derived from $\mathrm{RH}$ directly, but breakpoint locations are taken from those accepted in $q$ for each iteration respectively. On close analysis of the case study station set this homogenization process is found to perform well at removing spurious jumps in the candidate series while maintaining underlying trends (Fig. 3b). In theory, adjustments should be fairly evenly distributed, both over time and around zero, but perhaps with peaks in specific regions at times of broadscale instrument change. Such an analysis has been undertaken for all stations by region: the vast majority of adjustments are within $\pm 1 \mathrm{~g} \mathrm{~kg}^{-1}$ and relatively evenly spread over time (Fig. 4).

The quality controlled and homogenized data (3243 and 3128 stations for $q$ and $\mathrm{RH}$, respectively) are then converted to monthly mean anomalies (appendix A) and averaged over $5^{\circ}$ by $5^{\circ}$ grids. Gridbox means are simple averages with no attempt made to account for representativeness. Coverage remains good, especially in the Northern Hemisphere, with many grid boxes containing two or more stations (Fig. 2c).

\section{The marine component}

Marine observations are obtained from the International Comprehensive Ocean-Atmosphere Data Set (ICOADS) release 2.1 (Worley et al. 2005) from 1973 to 1997 . From 1998 onward, data are provided through the Global Telecommunications System (GTS), and made available on the Internet by the NOAA National Centers for Environmental Prediction (NCEP) (http:// icoads.noaa.gov/ncep_obs/). This combination of data 
TABLE 3. First and second stage quality control tests for the marine data and data removal summary as a percentage of all humidity data.

\begin{tabular}{|c|c|c|}
\hline Test & Description-the observation is removed if: & Data removed \\
\hline \multicolumn{3}{|c|}{ First stage } \\
\hline Bad position & $\begin{array}{l}\text { The observation position is not consistent with the ship track (based on ship and } \\
\text { wind speed). }\end{array}$ & $2 \%$ \\
\hline Bad location & The observation location is outside of $90^{\circ} \mathrm{N}-90^{\circ} \mathrm{S}, 180^{\circ} \mathrm{W}-180^{\circ} \mathrm{E}$ & $0 \%$ \\
\hline Bad date & The observation date is not possible: $1-31$ days, $1-12$ months. & $0.1 \%$ \\
\hline Over land & The observation is not over a water body. & $1.6 \%$ \\
\hline $\operatorname{Bad} T_{d}$ & The observation $T_{d}$ value is greater than $T$. & $0.3 \%$ \\
\hline Bad RH & $\begin{array}{l}\text { The observation } \mathrm{RH} \text { value is less than } 40 \% \text {. The oceans serve as a constant } \\
\text { moisture source and so marine } \mathrm{RH} \text { is thought not to fall lower than } 40 \% \text {. This } \\
\text { has since been found to not necessarily hold true over coastal regions where } \\
\text { advection of dry air is possible, and so future versions of HadCRUH will likely } \\
\text { modify this test. }\end{array}$ & $0.7 \%$ \\
\hline Bad $T$ & The observation $T$ value fails the outlier or homogeneity check. & $11.6 \%$ \\
\hline \multicolumn{3}{|c|}{ Second stage } \\
\hline Outlier & $\begin{array}{l}\text { The observation humidity value }(e, \mathrm{RH} \text { or } q) \text { is greater than four std dev from the } \\
\text { mean. }\end{array}$ & $0.18 \%$ \\
\hline Consistency check & $\begin{array}{l}\text { The observation humidity value ( } e \text { or } q \text { ) is not sufficiently similar to its neighbor } \\
\text { composite value (see Rayner et al. } 2003 \text { for criteria for creating neighbor } \\
\text { composites and respective similarity requirements). }\end{array}$ & $0.63 \%$ \\
\hline
\end{tabular}

sources is chosen for comprehensiveness, regularity of updates (GTS), and its use in numerous Hadley Centre marine datasets [e.g., the Hadley Centre Sea Ice and Sea Surface Temperature Dataset (HadISST); the Met Office Historical Marine Air Temperature datasets (MOHMAT43N and HadMAT1) (Rayner et al. 2003); HadSST2 (Rayner et al. 2006)]. Spatially, the marine component incorporates all oceans of the world, the Great Lakes, and the Caspian Sea. Coverage is good over the Northern Hemisphere midlatitudes and common ship tracks.

A number of issues specific to marine data compromise data accuracy. The daytime heating bias in marine air temperature (MAT) has been well documented (Parker et al. 1995; Rayner et al. 2003), but is not thought to affect humidity conversions (Kent and Taylor 1996). Changes in ship height, instrument type, and exposure and observing practices over time are found to cause biases, uncertainty, and inhomogeneity in several meteorological variables [MAT-Rayner et al. 2003; Berry and Kent 2005; sea surface temperature (SST)—Rayner et al. 2006]. Humidity measurements are not immune from such problems and previous attempts have been made to apply adjustments. However, these are, in most cases, to specific ships (height corrections-Kent et al. 1999) or instrument types (screen as opposed to psychrometer-measured humidities-Kent et al. 1993) and, because they are not able to be applied universally at the current time, are not deemed appropriate for application to HadCRUH, at least in this version.
The existing Hadley Centre Marine Data System (MDS), modified for use with HadCRUH, consists of a set of programs to undertake raw data extraction; conversion from $T$ and $T_{d}$ to $e, q$, and $\mathrm{RH}$; quality control; homogeneity (consistency) checks; and gridding and is well documented (Parker et al. 1995; Rayner et al. 2003; Allan and Ansell 2006; Rayner et al. 2006). It is run in two stages.

The first stage, summarized in Table 3, comprises seven tests to check for accurate placing in space and time and whether the observation is valid within reasonable physical expectations. The second stage, also documented in Table 3 , requires $e, q$, and RH climatologies and standard deviation fields to identify outliers and test consistency with neighbors. These fields cannot be created until the data are gridded. However, the gridding process requires climatology fields to first create anomalies. Thus, the first version climatologies are created from the NCEP reanalysis (Kalnay et al. 1996). Each individual data point passing through the first stage is anomalized by subtracting the relevant gridbox pentad climatology. Gridbox $\left(5^{\circ}\right.$ by $\left.5^{\circ}\right)$ monthly mean anomalies are then created by taking the winsorized means of all values in each box weighted by fractional area if applicable. Winsorizing, a technique common to Hadley Centre marine datasets and described in Rayner et al. (2006), reduces the effects of extreme values. New climatology and standard deviation fields are then created by adding the NCEP climatologies to the now gridded anomalies and recalculating. As such, any influence from the initial use of the 

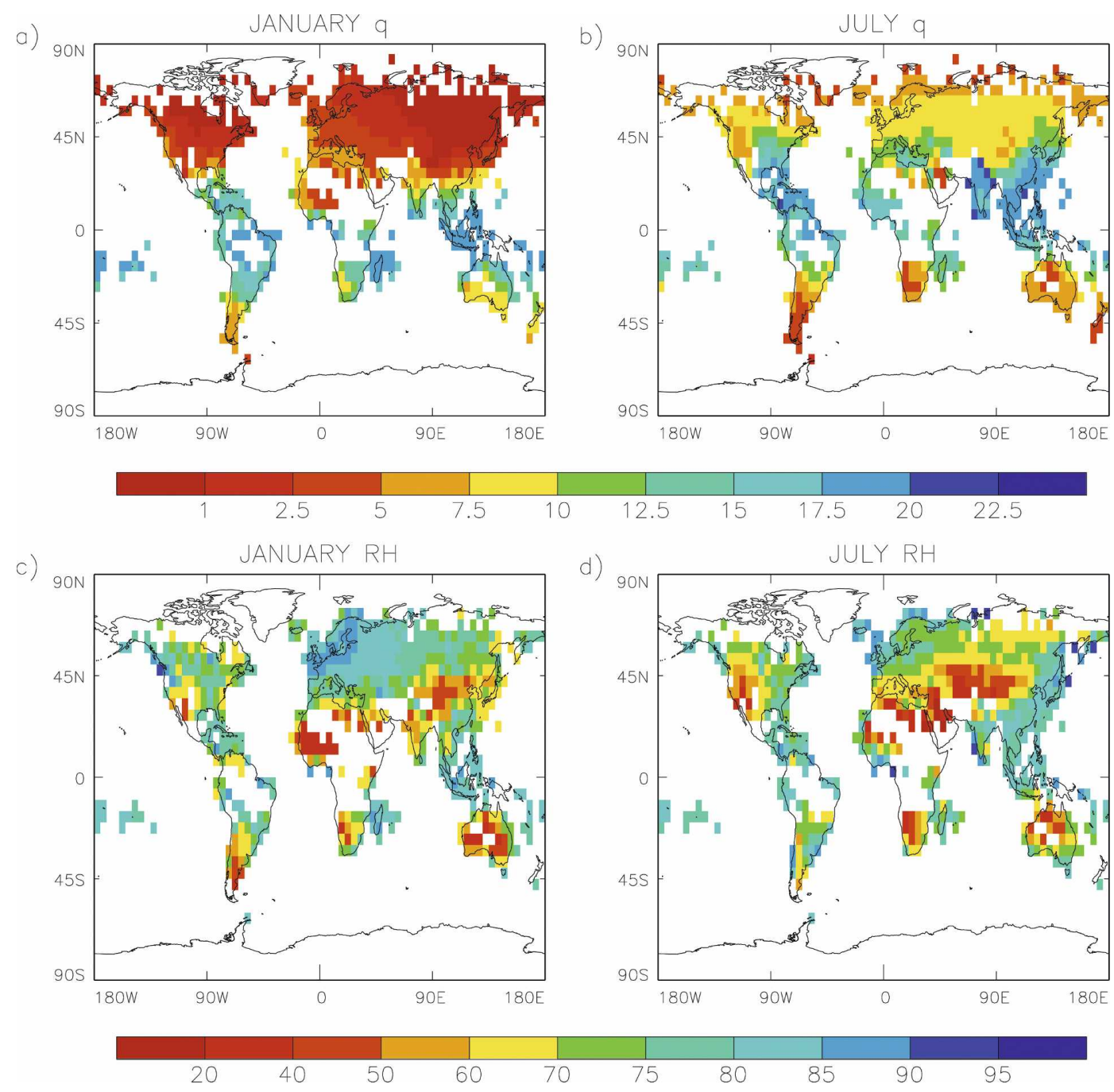

FIG. 5. HadCRUH land data climatological means over the period 1974-2003: (a) January $q$, (b) July $q$, (c) January RH, and (d) July RH. Panels for $q$ [(a) and (b)] are shown in $\mathrm{g} \mathrm{kg}^{-1}$ and panels for RH [(c) and (d)] are in $\%$.

NCEP reanalysis should be negligible. Monthly climatology fields are interpolated back to pentads from a nonlinear fit of the annual cycle, as for HadSST2 (Rayner et al. 2006).

At least two iterations of the second stage are considered necessary in order to have a climatology without influence from the observations failing the first iteration of outlier and neighbor consistency checks. Iterations, and the creation of new climatology and standard deviation fields, continue until further data removal falls below $0.5 \%$. Such a small fraction of data removal is unlikely to have a large effect on the end product. This threshold is reached after two iterations for HadCRUH.

The marine data cannot be homogenized in the same manner as the land data owing to its origin as mostly nonstationary point source data rather than fixed stations. Instead, each observation is compared with a composite of other observations close in space and time. No adjustments are made but, if the candidate observation is sufficiently different from the composite (depending on distance and time of composite stations-see Rayner et al. 2003; Willett 2007), it is removed.

Final data coverage is good in the Northern Hemisphere but poor in the Southern Hemisphere and high latitudes (Fig. 2d). Only the area between $70^{\circ} \mathrm{N}$ and $70^{\circ} \mathrm{S}$ is considered useful for analysis in HadCRUH. Temporally, data coverage is fairly consistent except for a $\sim 10 \%$ drop in 1997, recovering in 1998, coincident with the change from ICOADS to the GTS derived values. 

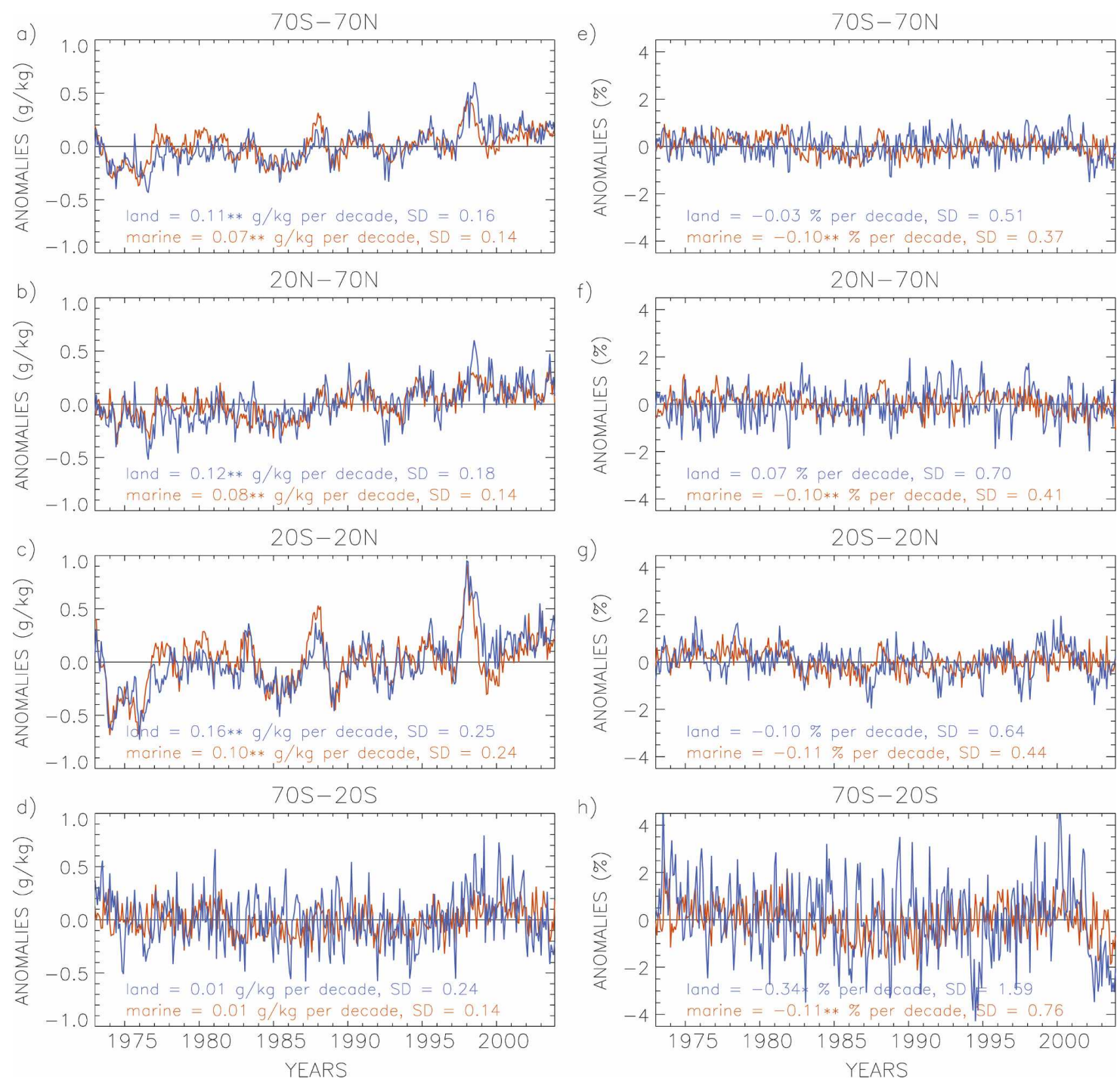

FIG. 6. HadCRUH regionally averaged land (blue) and marine (red) monthly mean anomaly time series and trends for the globe, hemispheres, and tropics over the period 1973-2003: (a)-(d) $q$; (e)-(f) RH. Trends are fitted and significance tested using restricted maximum likelihood estimation (REML) (Diggle et al. 1996) where a double (single) asterisk denotes significance at the $1 \%(5 \%)$ level.

\section{Recent changes in surface humidity}

\section{a. Humidity over land}

Climatology fields are created by averaging over the pentad climatologies for each station and then all station month climatologies for each grid box. Globally, monthly mean $q$ ranges from $>0$ to $20 \mathrm{~g} \mathrm{~kg}^{-1}$ and exhibits zonal continuity, with maxima in the tropics and summer hemisphere and decreasing poleward (Figs. $5 \mathrm{a}, \mathrm{b})$. The structure of $\mathrm{RH}$ is much less zonally continuous, with maxima in the Northern Hemisphere during winter and a global range of $\sim 10 \%-90 \%$ (Figs. $5 \mathrm{c}, \mathrm{d})$.
The land data are regionally averaged by weighting each grid box with the cosine of its latitude for the globe $\left(70^{\circ} \mathrm{S}-70^{\circ} \mathrm{N}\right)$, Northern Hemisphere $\left(20^{\circ}-70^{\circ} \mathrm{N}\right)$, Southern Hemisphere $\left(70^{\circ}-20^{\circ} \mathrm{S}\right)$, and the deep tropics $\left(20^{\circ} \mathrm{S}-20^{\circ} \mathrm{N}\right)$ (after Thorne et al. 2005; Karl et al. 2006). Seasonal averages are also created and categorized as follows: December-February (DJF); March-May (MAM); June-August (JJA); and September-November (SON). The seasonal and annual time series in $q$ (Figs. 6a-d and Table 4) show positive and significant (at the 1\% level) trends for all regions and seasons except the Southern Hemisphere. Trends are strongest in the tropics (over all months) and Northern Hemi- 
TABLE 4. Regionally averaged trends in $q$ and $\mathrm{RH}$ for the whole time series (ALL) and each season. Trends are fitted and significance tested using REML (Diggle et al. 1996) where an asterisk (caret) denotes significance at $1 \%(5 \%)$ level.

\begin{tabular}{|c|c|c|c|c|c|c|c|c|c|c|}
\hline \multirow[b]{2}{*}{ Region } & \multicolumn{5}{|c|}{$q\left[\mathrm{~g} \mathrm{~kg}^{-1}(10 \mathrm{yr})^{-1}\right]$} & \multicolumn{5}{|c|}{$\mathrm{RH}\left[\%(10 \mathrm{yr})^{-1}\right]$} \\
\hline & ALL & DJF & MAM & JJA & SON & ALL & DJF & MAM & JJA & SON \\
\hline & \multicolumn{10}{|c|}{ Land } \\
\hline Globe $\left(70^{\circ} \mathrm{S}-70^{\circ} \mathrm{N}\right)$ & $0.11 *$ & $0.11 *$ & $0.09 *$ & $0.15^{*}$ & $0.11 *$ & -0.03 & 0.09 & $-0.19^{\wedge}$ & -0.08 & -0.04 \\
\hline Northern Hemisphere $\left(20^{\circ}-70^{\circ} \mathrm{N}\right)$ & $0.12 *$ & $0.09 *$ & $0.08 *$ & $0.20 *$ & $0.11 *$ & 0.07 & 0.26 & -0.18 & 0.08 & 0.12 \\
\hline Deep tropics $\left(20^{\circ} \mathrm{S}-20^{\circ} \mathrm{N}\right)$ & $0.16^{*}$ & $0.20 *$ & $0.14^{*}$ & $0.13^{*}$ & $0.18^{*}$ & -0.10 & -0.12 & -0.16 & $-0.22^{\wedge}$ & -0.10 \\
\hline \multirow[t]{2}{*}{ Southern Hemisphere $\left(70^{\circ}-20^{\circ} \mathrm{S}\right)$} & 0.01 & 0.02 & -0.00 & -0.02 & 0.00 & $-0.34^{\wedge}$ & -0.30 & -0.32 & -0.64 & -0.57 \\
\hline & \multicolumn{10}{|c|}{ Marine } \\
\hline Globe & $0.07 *$ & 0.06 & $0.06 *$ & $0.07^{\wedge}$ & $0.08^{\wedge}$ & $-0.10 *$ & -0.14 & -0.08 & -0.05 & -0.14 \\
\hline Northern Hemisphere & $0.08 *$ & 0.05 & $0.06^{\wedge}$ & $0.14 *$ & $0.12 *$ & $-0.10^{*}$ & -0.20 & -0.09 & $0.26^{\wedge}$ & 0.12 \\
\hline Deep tropics & $0.10^{*}$ & $0.13^{\wedge}$ & $0.12 *$ & $0.10^{\wedge}$ & $0.11^{\wedge}$ & -0.11 & -0.04 & -0.09 & -0.09 & -0.13 \\
\hline Southern Hemisphere & 0.01 & -0.01 & -0.00 & -0.03 & -0.02 & $-0.11 *$ & -0.23 & -0.05 & -0.29 & -0.28 \\
\hline
\end{tabular}

sphere summer at 0.16 and $0.20 \mathrm{~g} \mathrm{~kg}^{-1}(10 \mathrm{yr})^{-1}$, respectively, relative to a global trend (over all months) of $0.11 \mathrm{~g} \mathrm{~kg}^{-1}(10 \mathrm{yr})^{-1}$. At the gridbox level trends show strong spatial continuity (Figs. 7a-e). Moistening is widespread with drying isolated to western North America, central South America, South Africa, and Australia. There are considerable seasonal differences in the patterns of moistening and drying. Of interest is the comprehensive moistening from the tropics northward in the JJA season, but there are conspicuous drying patches in other seasons, especially over North America. Following the Clausius-Clapeyron relation, changes in $q$ with increasing $T$ should be largest in regions of higher ambient $T$ if $\mathrm{RH}$ remains approximately constant. This is consistent with finding maximum trends in the tropics and Northern Hemisphere in summer. Until the completion of HadCRUH, humidity was an unused diagnostic for formal detection and attribution studies. The strong signals apparent in these regions/seasons have been found to make $q$, in particular, a valuable variable for attribution of recent climate change to human activities (Willett et al. 2007).

Trends in RH are small and not significant for the globe, Northern Hemisphere, and tropics (Figs. 6e-h) supporting the theory of a quasi-constant RH over large spatial scales. They are negative except for the Northern Hemisphere. This is also true for the majority of seasonally averaged trends (Table 4) of which all but two are not significant. All trends are negative except for those averaged over the Northern Hemisphere (DJF, JJA, and SON) and globe (DJF only). Trends at gridbox resolution (Figs. 8a-e), for which significance is not assessed, exhibit patchy but regionally consistent trends where relative drying is prevalent, the exceptions being southeast North America, the western coast of North Africa, and south-central and northeast Asia where moistening is occurring. In contrast to the homo- geneous Northern Hemisphere JJA $q$ trends, there is strong relative drying over Europe and East Asia but relative moistening over Central Asia.

\section{b. Humidity over the oceans}

Similar to the land data, climatological marine $q$ has a strong zonal structure peaking in the tropics and decreasing poleward (Figs. 9a,b), ranging from $\sim 1$ to $20 \mathrm{~g}$ $\mathrm{kg}^{-1}$. Climatologically, $\mathrm{RH}$ varies very little over the oceans (Figs. 9c,d) and is largely between $70 \%$ and $90 \%$. It is highest in the high latitudes, especially in the summer hemisphere. However, this is in the region of very poor sampling density and there is markedly little confidence in values at latitudes poleward of $45^{\circ} \mathrm{S}$ and $70^{\circ} \mathrm{N}$ (similar to other datasets using the same marine source data, i.e., HadCRUT3-Brohan et al. 2006).

The data are regionally averaged as for the land. For $q$, all trends including all seasonally averaged trends, except in the Southern Hemisphere, are positive and, with the exception of the global and Northern Hemisphere DJF season, significant (Figs. 6a-d and Table 4). The largest trends are found in the tropics and Northern Hemisphere JJA season. Although generally weaker than over the land and with slightly lower variability, the size and sign of trends are comparable. Gridbox trends (Figs. 7a-e) show overall moistening but with some drying regions in the Southern Hemisphere and seasonally the northern Pacific (DJF). Trends in RH (Fig. 6e-h) are negative and significant at the $1 \%$ level except for the tropics. This contradicts the assumption of constant RH over time and is not consistent with the land data. This may be linked to an apparent artificial moist bias in the marine humidity data prior to 1982 (discussed below). For seasonal averages (Table 4) all are negative except for the Northern Hemisphere in JJA and SON. Only the trend for 
a)

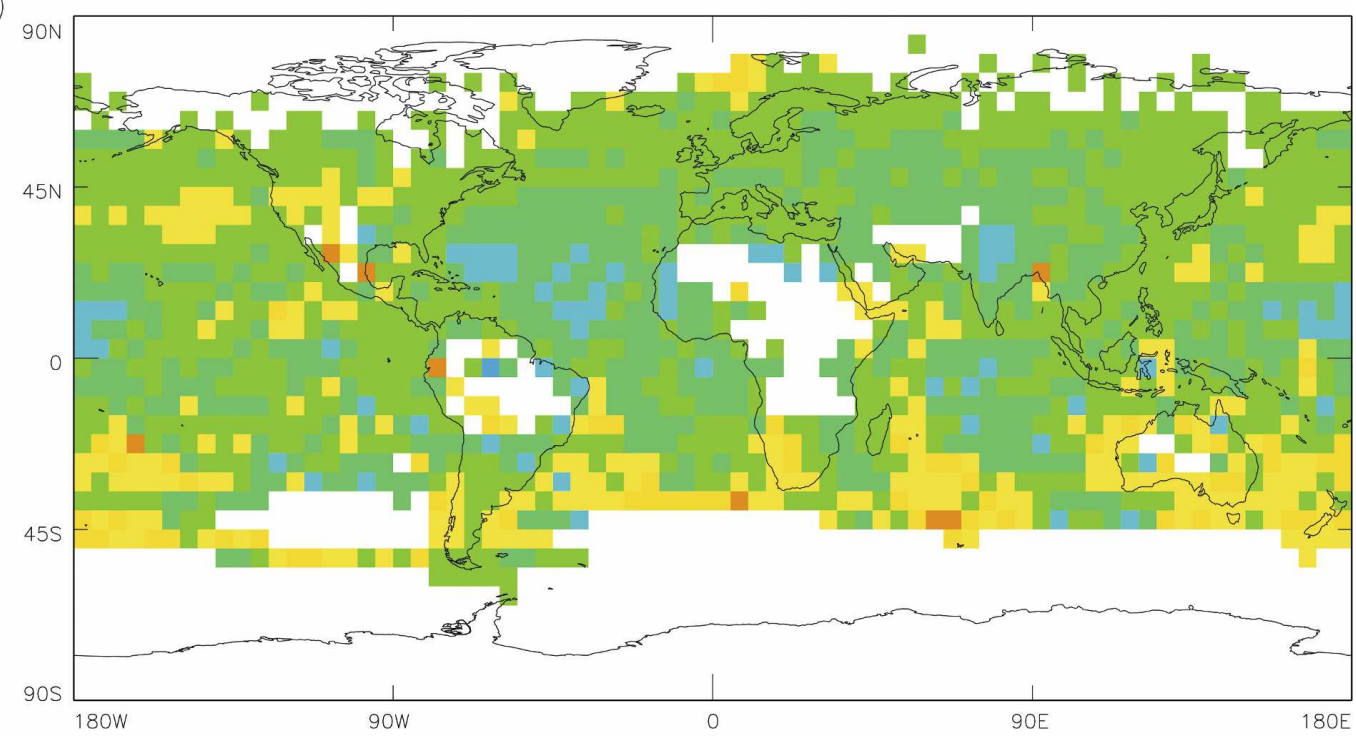

b)

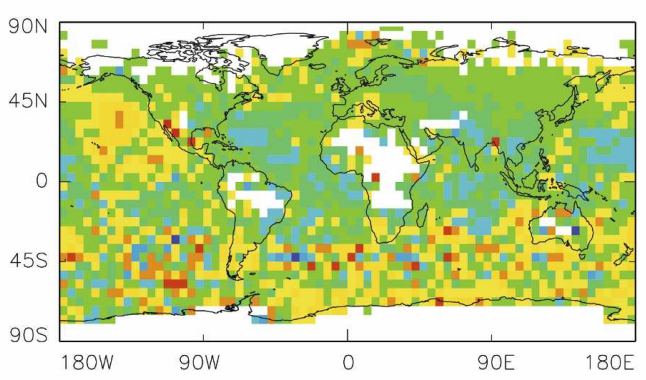

d)

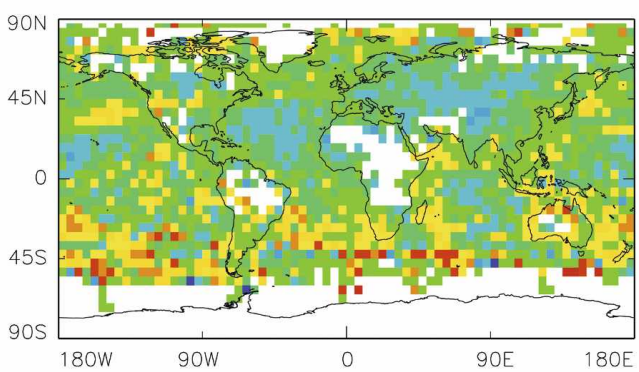

c)

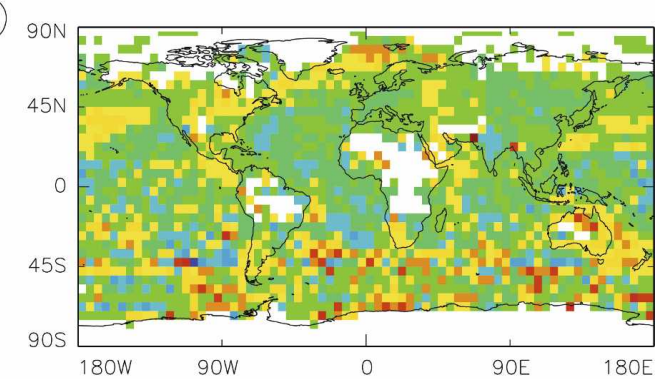

e)

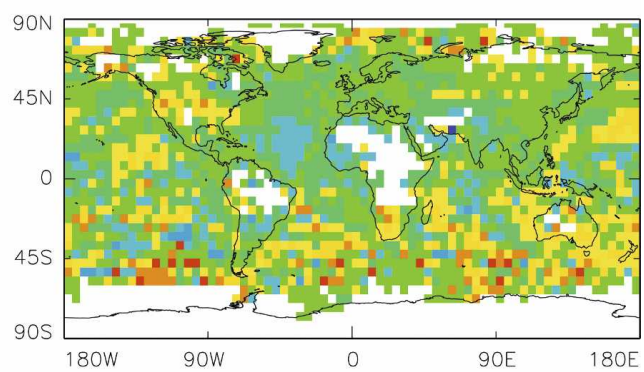

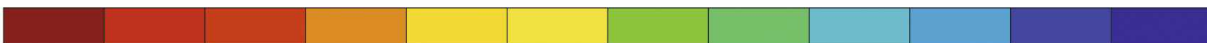

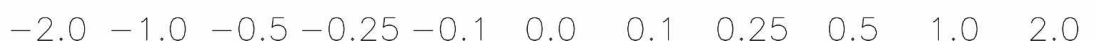

FIG. 7. Gridbox trends for $q$ for the period 1973-2003 for (a) the calendar year, (b) DJF seasonal average, (c) MAM seasonal average, (d) JJA seasonal average, and (e) SON seasonal average. Units are in $\mathrm{g} \mathrm{kg}^{-1}(10 \mathrm{yr})^{-1}$. Trends are fitted using the median of pairwise slopes (Lanzante 1996) where at least $50 \%$ of months (seasons) must be present to fit trends. As only two months per season are required to create seasonal averages, a grid box may have seasonal trends present but no calendar year trend.

the Northern Hemisphere in JJA is significant. Variability is smaller than in the land data.

\section{c. A shift in marine humidity in 1982?}

In the marine $q$ and especially $\mathrm{RH}$, there is a noticeable shift in the mean after 1982 (Fig. 6), most apparent in the Southern Hemisphere. The shift in magnitude is large relative to trends such that, if this is not a real climate phenomenon, $\mathrm{RH}$ trends could be much closer to zero (less negative) and $q$ trends more positive. A comparable shift is not evident in SST and MAT time series from HadSST2 and HadMAT1 (Rayner et al. 
c)

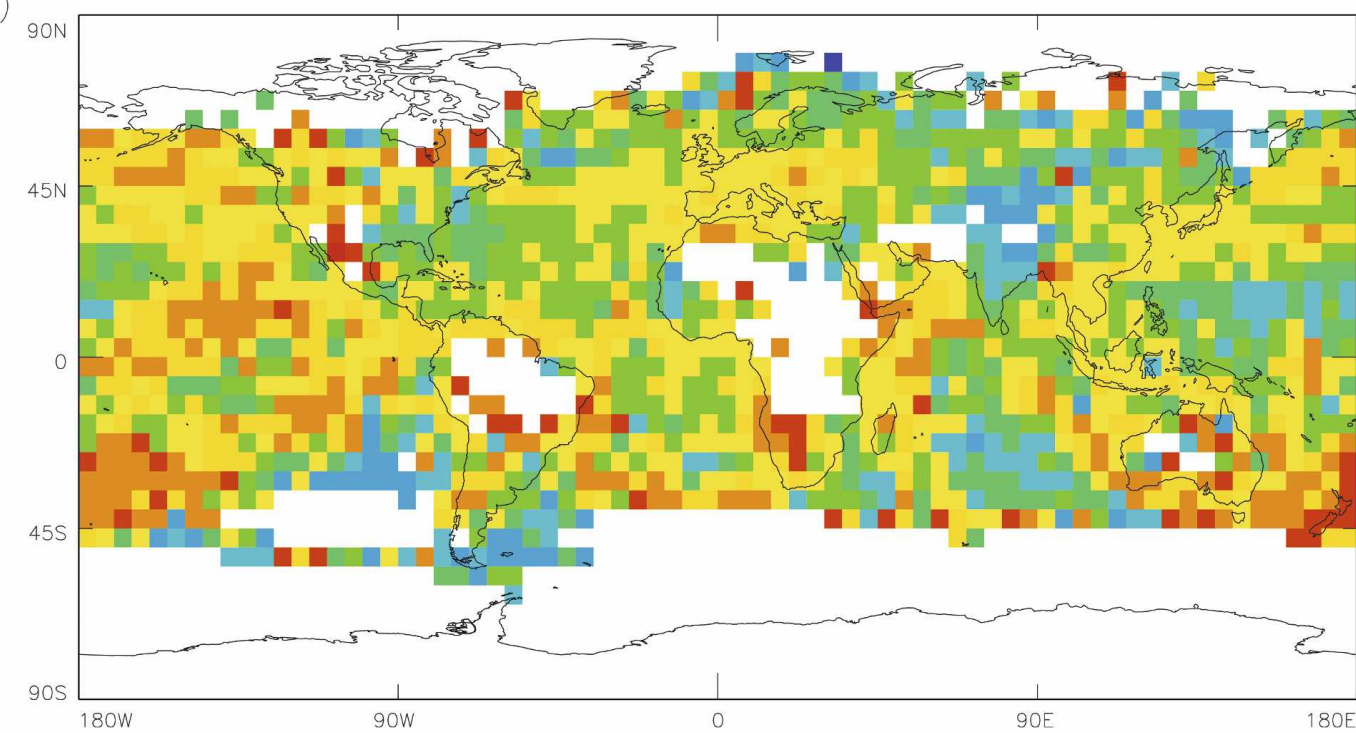

b)

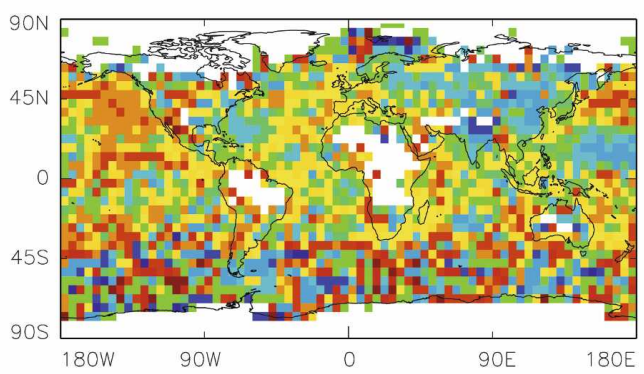

c) $90 \mathrm{~N}$

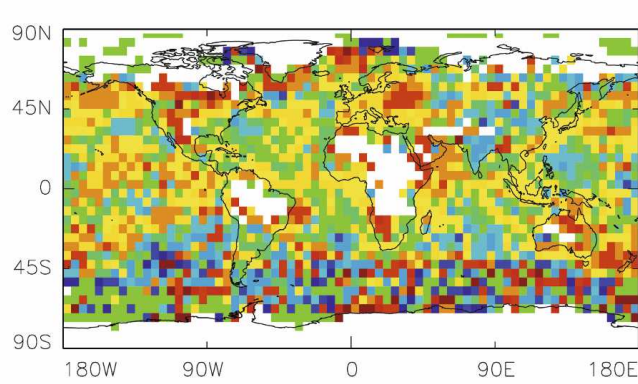

d)

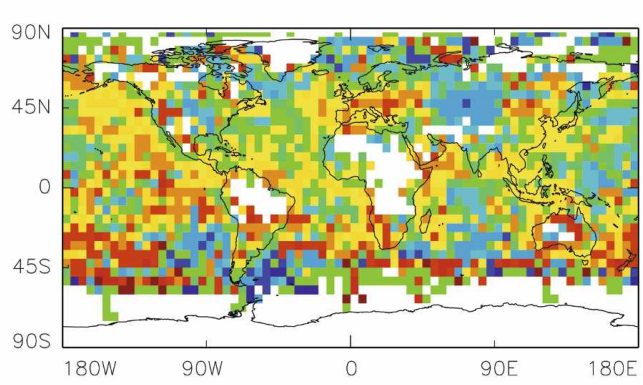

e) 900
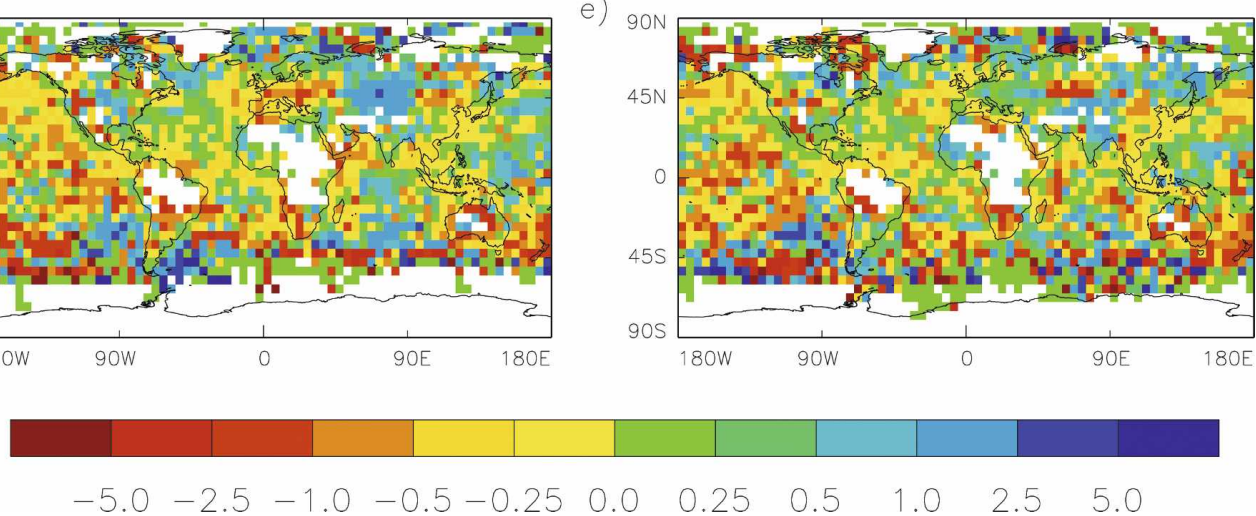

FIG. 8. As in Fig. 7 but for RH (\%).

2003; Rayner et al. 2006) nor in the HadCRUH land data, isolating this as a marine humidity issue and likely not of climatic origin. Although a strong ENSO event does occur in 1982, it is not believed to be responsible for such a strong and persistent shift in climate. A $t$ test on the marine time series four years before and after 1982 at gridbox resolution reveals widespread significant differences with regional coherency (Fig. 10). This is a pervasive but not global problem and not limited to or particularly focused on typical ENSO regions.

Owing to space restrictions on the GTS, until 1 January 1982 many ships recorded $T_{d}$ values as whole numbers (rounding up or down) as opposed to having decimal places (J. Kennedy 2006, personal communication; additional information is available online at http:// icoads.noaa.gov/e-doc/lmr). Plotting the frequency of 
a)

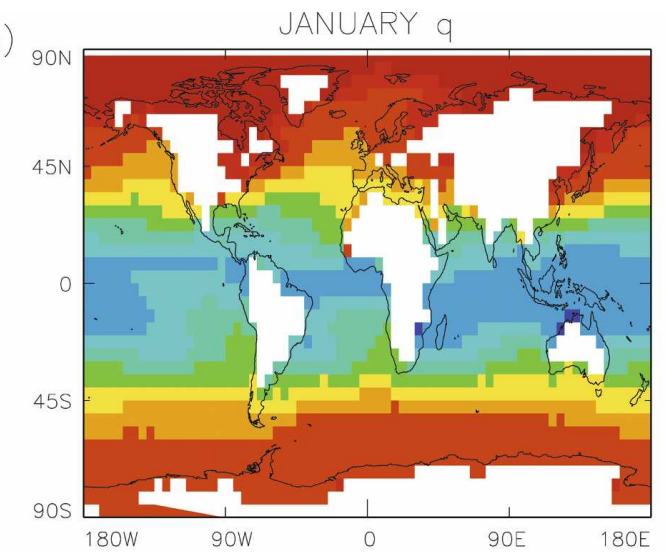

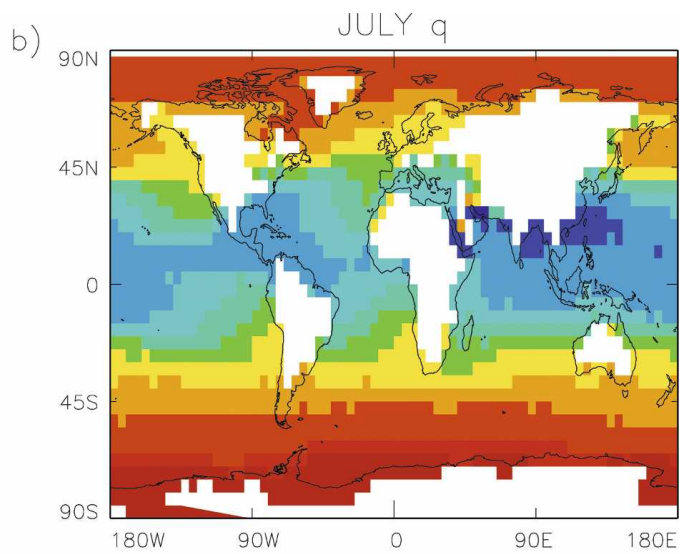
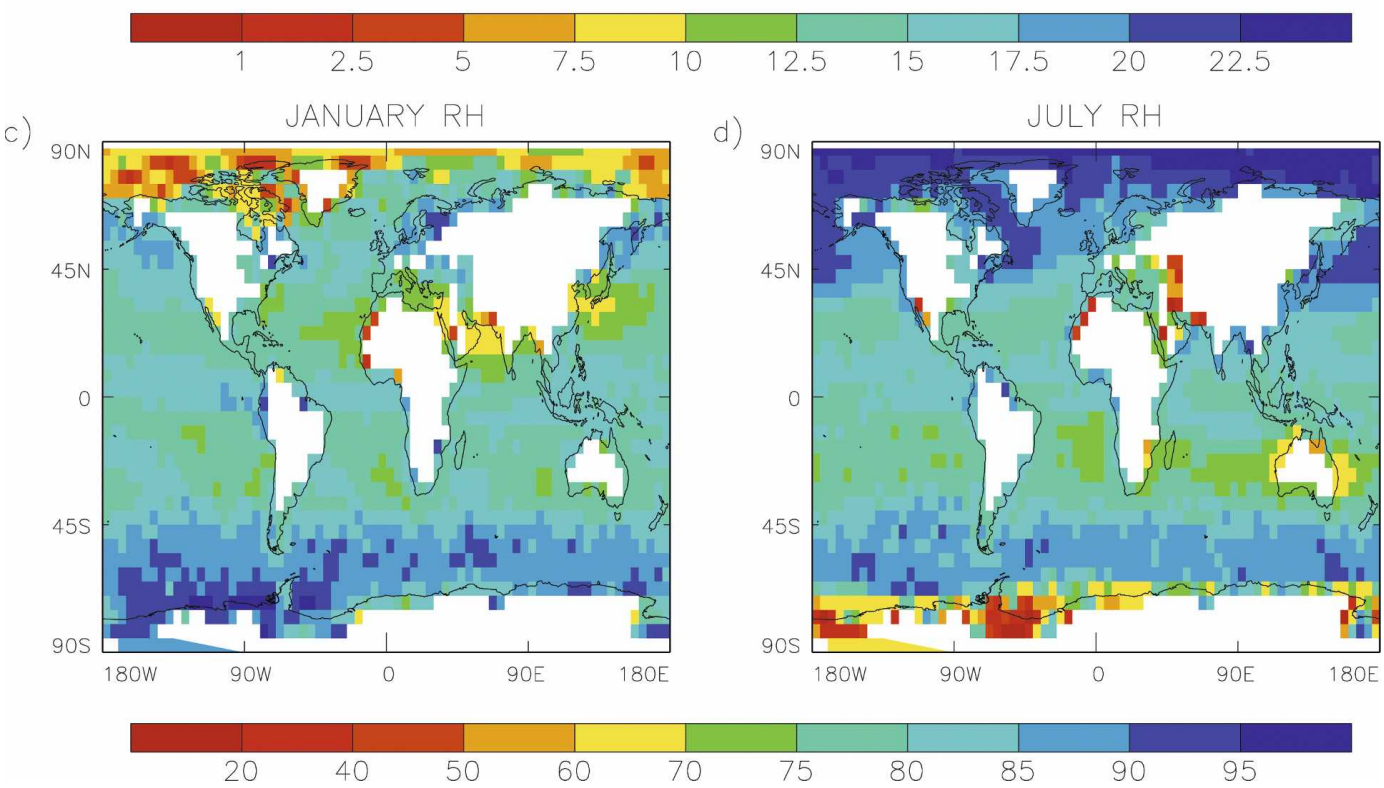

20 40 50 60 70

RUH marine data.

each decimal place for $T_{d}$ data for an equal period of time before and after 1982 indicates a clear discontinuity at this time (Fig. 11). This change in practice can be further attributed to 5 out of the 11 observing decks (an ID referring to a specific fleet, country or organization that ships, buoys, etc. collectively report under) present over the period. This collectively accounts for $74.4 \%$ and $79.4 \%$ of data before and after 1982, respectively, and is thus the likely cause. There was no recognized convention on rounding method to convert observations to whole numbers, so it is likely that a variety of conventions were used. For the magnitude and persistence of the positive bias seen, a widespread practice of rounding up would have had to have occurred. However, there is no available metadata to our current knowledge to confirm that this was the case and, therefore, definitively conclude that this is the reason for the apparent jump.
An attempt is made to apply adjustments for this 1982 shift by calculating the trend in land minus marine humidity for coastal grid boxes (containing both land and marine data) averaged for the globe (Figs. 12a,b). The shift is clear in $q$ with reasonable consistency within these independently derived data both before and after 1982. Of note is a second steplike change in 1998, apparently persisting until 2002. This has not been investigated here. The implied $q$ adjustment trend is comparable to the marine global mean trend and significant at $1 \%\left[0.05 \mathrm{~g} \mathrm{~kg}^{-1}(10 \mathrm{yr})^{-1}\right]$. If applied as a first-order error adjustment to the marine humidity data a new global marine trend of $0.12 \mathrm{~g} \mathrm{~kg}^{-1}(10 \mathrm{yr})^{-1}$ results, much closer to trends over land $\left[0.11 \mathrm{~g} \mathrm{~kg}^{-1}\right.$ $(10 \mathrm{yr})^{-1}$ ]. The implied RH trend adjustment is not significant, possibly due to the greater high frequency variability than in $q$, but at $0.04 \%(10 \mathrm{yr})^{-1}$ would bring the global marine RH trend closer to zero. However, 


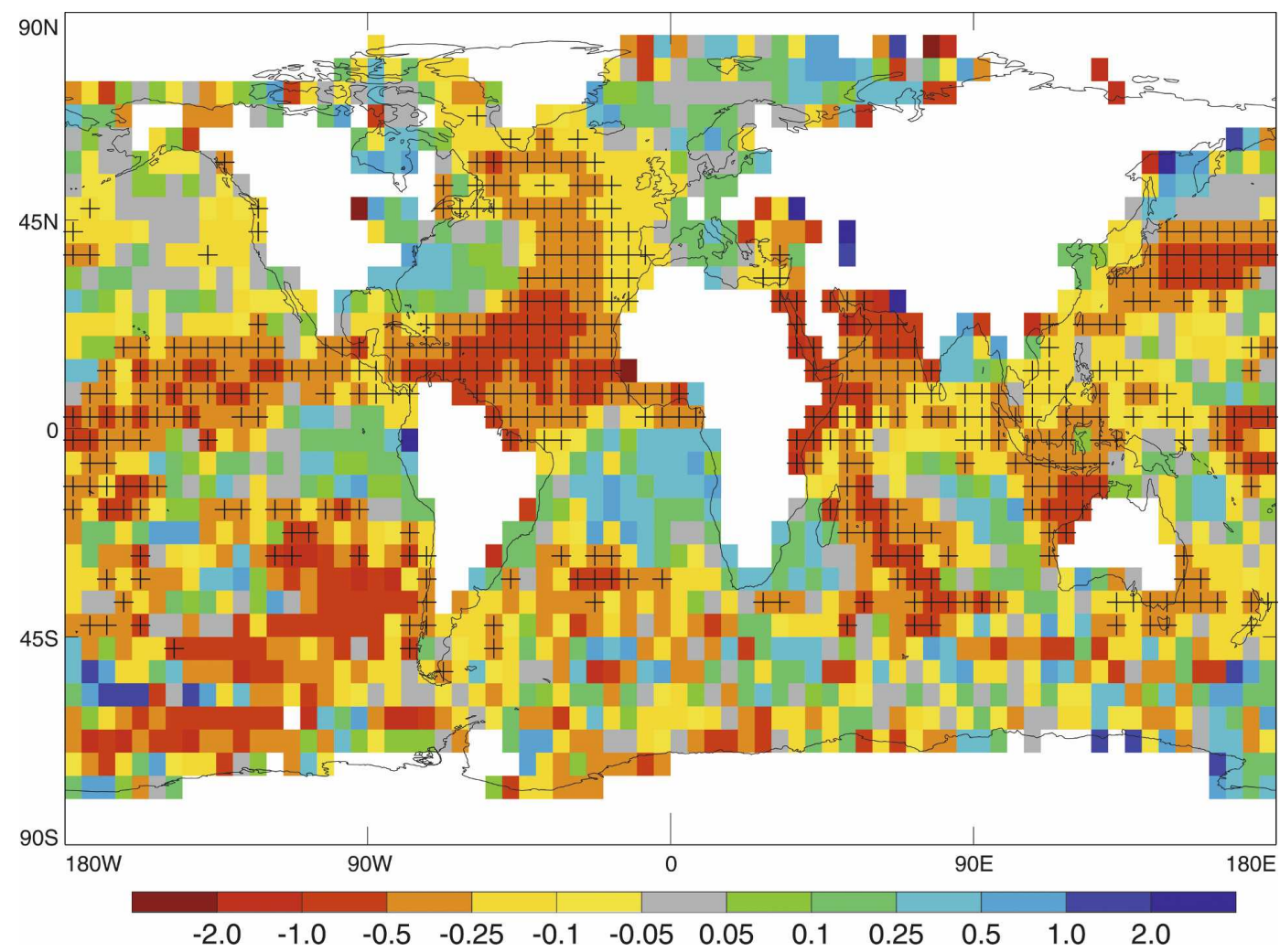

FIG. 10. Difference map of mean anomaly $q$ 1983-86 minus 1978-81. Units are in $\mathrm{g} \mathrm{kg}^{-1}$. Crosses show grid boxes with significantly different time series (at the 0.05 level using a $t$ test) before and after the 1982 shift.

these adjustments are not applied to the end product of HadCRUH because the true cause is not yet conclusively identified, and the shift is not entirely global such that any adjustment should be applied only to affected decks or even specific observing platforms (if it can be isolated this way). Importantly, not adjusting the data likely results in smaller marine $q$ trends and RH trends more negative than in reality. For the postshift period 1982-2003 (Table 5), all trends are more positive. No-

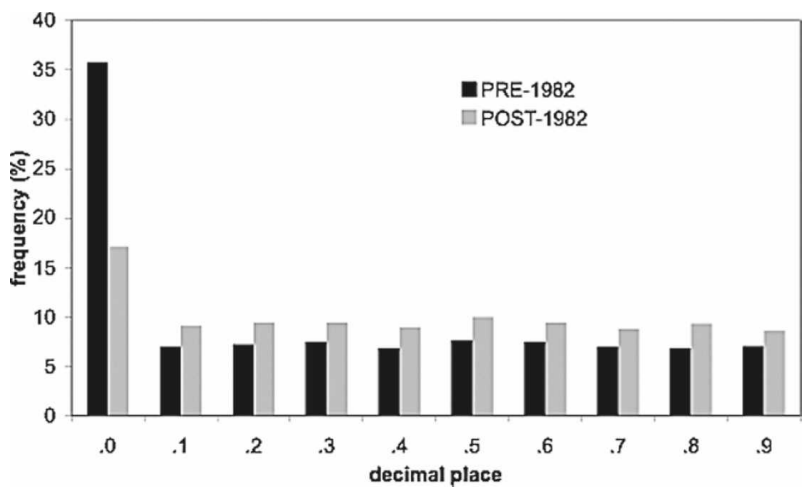

FIG. 11. Frequency of decimal places in marine $T_{d}$ data for nine years before (black) and after (gray) the 1982 apparent shift. tably, the significant negative RH trends for the globe, Southern Hemisphere, and tropics become positive and significant, therefore still not supporting the assumption that $\mathrm{RH}$ remains largely constant over time, at least over the oceans. Conversely, Northern Hemisphere trends become closer to zero and not significant. This is a region of higher data density and likely better data quality. Given the remaining uncertainties, drawing any conclusions regarding constant $\mathrm{RH}$ based on the marine data is not possible.

\section{Summary}

There are sufficient data of adequate quality available to create near-global land and marine surface humidity datasets suitable for climate analyses. Climatological surface $q$ is strongly zonal in pattern decreasing meridionally from the tropical zone of the summer hemisphere. $\mathrm{RH}$ is regionally coherent with less zonal structure over land. In absolute terms $(q)$, atmospheric surface moisture has increased significantly over both land and ocean since 1973 when averaged over the globe [land $=0.11 \mathrm{~g} \mathrm{~kg}^{-1}(10 \mathrm{yr})^{-1}$; marine $=0.07 \mathrm{~g}$ $\left.\mathrm{kg}^{-1}(10 \mathrm{yr})^{-1}\right]$, Northern Hemisphere, and tropics and 
a)

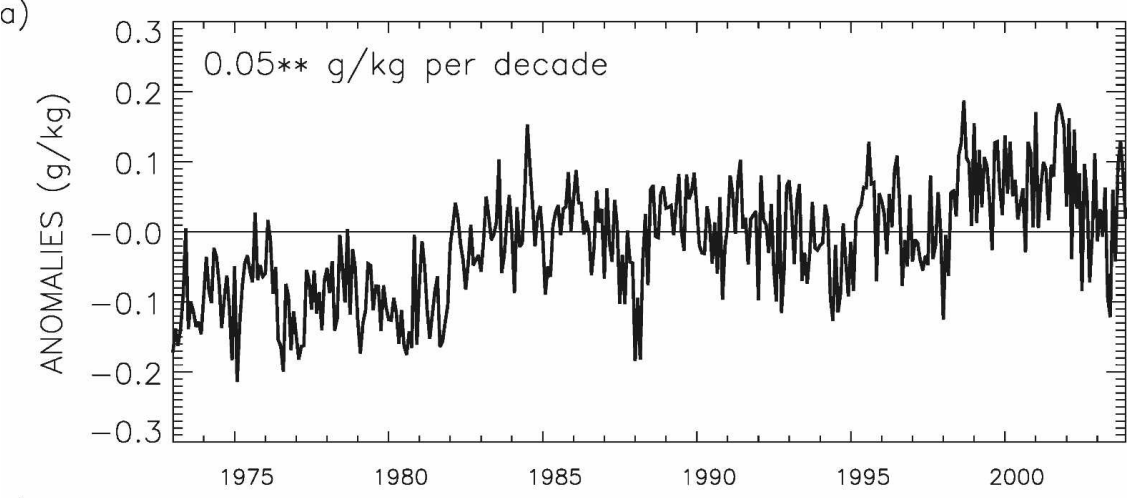

b)

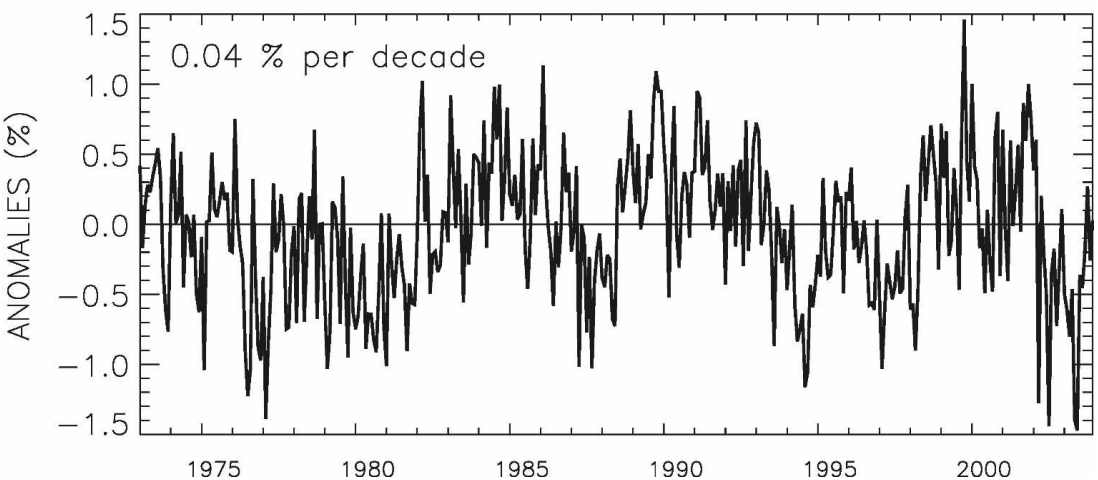

FIG. 12. Globally averaged difference series and trends of (land - marine) data in coastal grid boxes for monthly mean anomaly (a) $q$ and (b) RH. Trends are fitted using the REML method where double asterisk shows significance at the $1 \%$ level.

for all seasons. Trends are larger over land; however, it is highly likely that the pre-1982 marine data have an artificial moist bias, most probably arising from the pervasive practice of only recording whole numbers on some ships until 1 January 1982, dampening actual trends. The largest significant $q$ trends are in the tropics [land $=0.16 \mathrm{~g} \mathrm{~kg}^{-1}(10 \mathrm{yr})^{-1}$; marine $=0.10 \mathrm{~g} \mathrm{~kg}^{-1}$ $\left.(10 \mathrm{yr})^{-1}\right]$ and Northern Hemisphere during summer $\left[\right.$ land $=0.20 \mathrm{~g} \mathrm{~kg}^{-1}(10 \mathrm{yr})^{-1}$; marine $=0.14 \mathrm{~g} \mathrm{~kg}^{-1}$ $(10 \mathrm{yr})^{-1}$ ], where ambient $T$ is higher leading to larger increases in $q$, in accordance with the ClausiusClapeyron relation.

TABLE 5. Comparison of regionally averaged $q$ and RH trends for the whole period compared to the post-1982 period. Trends are fitted and significance tested using REML (Diggle et al. 1996) where an asterisk (caret) denotes significance at the $1 \%(5 \%)$ level.

\begin{tabular}{crcrc}
\hline \hline $\begin{array}{c}\text { Trend period } \\
\text { and variable }\end{array}$ & Globe & $\begin{array}{c}\text { Northern } \\
\text { Hemisphere }\end{array}$ & Tropics & $\begin{array}{c}\text { Southern } \\
\text { Hemisphere }\end{array}$ \\
\hline $1982-2003 q$ & $0.12^{*}$ & $0.14^{*}$ & $0.11^{\wedge}$ & $0.09^{*}$ \\
$1973-2003 q$ & $0.07^{*}$ & $0.08^{*}$ & $0.10^{*}$ & 0.01 \\
$1982-2003 \mathrm{RH}$ & $0.14^{*}$ & -0.04 & $0.18^{*}$ & $0.25^{*}$ \\
$1973-2003 \mathrm{RH}$ & $-0.10^{*}$ & $-0.10^{*}$ & -0.11 & $-0.11^{*}$ \\
\hline
\end{tabular}

For RH, trends are mostly negative and not significant over land, giving support to the theory of constant $\mathrm{RH}$ over large spatial and temporal scales. Marine RH is complicated by the widespread discontinuity in 1982 where trends for the entire period of record are apparently negative and significant becoming positive and significant (with the exception of the Northern Hemisphere, which becomes closer to zero and not significant) for the post-1982 period. (HadCRUH is now freely available for download at http://www.hadobs. org.)

Acknowledgements. We thank Neal Lott and Russ Vose (NCDC, Ashville, NC, United States) for providing the ISD land data and for advice and Philip Brohan (Met Office Hadley Centre, United Kingdom) for making the marine data available, providing the Marine Data System code and for help and advice. We recognize the input and advice given from everyone in the Climate Variability group at the Met Office Hadley Centre, in particular David Parker for various coding and insight into issues encountered and John Kennedy for input on the marine data shift. We acknowledge Mike Salmon for technical support. Katharine Willett 
was supported by a CASE studentship from the U.K. Natural Environment Research Council and the Met Office (Ref: NER/S/A/2003/11220). Katharine Willett was also supported while preparing results for publication by funding from Nathan Gillett's Philip Leverhulme Prize. Nathan Gillett and Phil Jones acknowledge support of the Climate Change Detection and Attribution Project, jointly funded by the NOAA Office of Global Programs and the U.S. Department of Energy, Grant DE-FG02-98ER62601. Peter Thorne was supported by the Joint DEFRA and MoD Programme, (DEFRA) GA01101 (MoD) CBC/2B/0417_ANNEX $\mathrm{C}^{\circ}$ and through his contribution this paper is British Crown copyright.

\section{APPENDIX A}

\section{Creating Pentad and Monthly Mean Anomalies}

A pentad is a 5-day mean. There are 73 per year with 6 per month except for August, which has 7. The twelfth pentad has 29 February added in every leap year. Compared to daily resolution pentads are computationally more convenient and avoid the problems with large variance characteristic of daily data for homogenization. They also provide the opportunity to reproduce a higher-resolution dataset at a later date. For all variables $\left(T, T_{d}, e, q\right.$, and $\left.\mathrm{RH}\right)$ pentad mean anomalies (PMA) are created by creating hourly pentad climatologies (HPC) (e.g., all observations at $00 \mathrm{~h}$ between 1 and 5 January from 1974 to 2003 are averaged). Hourly anomalies are created for each observation by subtracting the corresponding HPC, thus removing the diurnal cycle. All hourly anomalies within each pentad of each year are averaged to give a PMA value. At least three days of data are required to create a pentad. Pentad mean climatologies are made by averaging over each HPC. Absolute pentads are created by adding back the corresponding pentad mean climatology to the PMA.

Monthly mean anomalies are made by averaging over the PMAs for each month, where at least three PMAs are present. This gives slightly larger monthly mean anomalies than if calculated directly from hourly data (Taylor et al. 2000; Rayner et al. 2006), but maintains consistency with the marine component of HadCRUH.

\section{APPENDIX B}

\section{Creating Neighbor Composites}

Using a similar convention to that of Briffa and Jones (1993) and Thorne et al. (2005), all stations within a potential correlation region of $10^{\circ}$ latitude and $50^{\circ}$ longitude on either side of the candidate station are potential neighbors. NCEP reanalysis monthly mean $(q$ and RH) anomalies for 1973-2003 (Kalnay et al. 1996) are used to create an actual correlation region for each station. This consists of all grid boxes $\left(1^{\circ}\right.$ by $\left.1^{\circ}\right)$ within the potential correlation region that correlate with the candidate station gridbox time series with an $r$ value greater than the $e$-folding distance (1/2.7183). All stations within those grid boxes and within 1000-m elevation of the candidate station become actual neighbor stations and are given the gridbox $r$ value as a weighting coefficient. The elevation requirement accounts for the poorer spatial continuity of humidity vertically than horizontally and the possibility that NCEP reanalyses may not represent this accurately. A neighbor composite is made by creating a weighted average over all actual neighbors with a caveat that there must be at least five neighbors to avoid spurious breakpoint assignment as much as possible. A difference series is also created of the candidate station minus neighbor composite.

\section{REFERENCES}

Allan, R. J., and T. Ansell, 2006: A new globally complete monthly historical mean sea level pressure data set (HadSLP2): 1850-2004. J. Climate, 19, 5816-5842.

Allen, M. R., and W. J. Ingram, 2002: Constraints on future changes in climate and the hydrological cycle. Nature, 419, 224-232.

Anthes, R. A., R. W. Corell, G. Holland, J. W. Hurrell, M. C. MacCracken, and K. E. Trenberth, 2006: Hurricanes and global warming-Potential linkages and consequences. Bull. Amer. Meteor. Soc., 87, 623-628.

Arrhenius, S., 1896: On the influence of carbonic acid in the air upon the temperature of the ground. Philos. Mag., 41, 237276.

Berry, D. I., and E. C. Kent, 2005: The effect of instrument exposure on marine air temperatures: An assessment using VOSClim Data. Int. J. Climatol., 25, 1007-1022.

Briffa, K. R., and P. D. Jones, 1993: Global surface air temperature variations during the twentieth century: Part 2, implications for large-scale high-frequency palaeoclimatic studies. Holocene, 3, 77-88.

Brohan, P., J. J. Kennedy, I. Harris, S. F. B. Tett, and P. D. Jones, 2006: Uncertainty estimates in regional and global observed temperature changes: A new dataset from 1850. J. Geophys. Res., 111, D12106, doi:10.1029/2005JD006548.

Buck, A. L., 1981: New equations for computing vapor pressure and enhancement factor. J. Appl. Meteor., 20, 1527-1532.

Dai, A., 2006: Recent climatology, variability, and trends in global surface humidity. J. Climate, 19, 3589-3606.

Davey, C. A., R. A. Pielke Sr., and K. P. Gallo, 2006: Differences between near-surface equivalent temperature and temperature trends for the Eastern United States-Equivalent temperature as an alternative measure of heat content. Global Planet. Change, 54, 19-32.

Diggle, P. J., K. Y. Liang, and S. L. Zeger, 1996: General linear 
models for longitudinal data. Analysis of Longitudinal Data, Vol. 13, Oxford Statistical Science Series, Oxford University Press, 54-70.

Easterling, D. R., and T. C. Peterson, 1995: A new method for detecting undocumented discontinuities in climatological time series. Int. J. Climatol., 15, 369-377.

, T. R. Karl, J. H. Lawrimore, and S. A. Del Greco, cited 1999: United States historical climatology network daily temperature, precipitation, and snow data for 1871-1997. NOAA ORNL/CDIAC-118, NDP-070. [Available online at http:// cdiac.esd.ornl.gov/epubs/ndp/ndp070/ndp070.html.]

Elliott, W. P., 1995: On detecting long-term changes in atmospheric moisture. Climatic Change, 31, 349-367.

Gaffen, D. J., and R. J. Ross, 1999: Climatology and trends of U.S surface humidity and temperature. J. Climate, 12, 811-828.

Goff, J. A., 1957: Saturation pressure of water on the new Kelvin temperature scale. Proc. Semi-annual Meeting of the American Society of Heating and Ventilating Engineers, Murray Bay, QC, Canada, American Society of Heating and Ventilating Engineers, 347-354.

— , and S. Gratch, 1946: Low-pressure properties of water from $-160^{\circ} \mathrm{F}$ to $212^{\circ} \mathrm{F}$. Trans. Amer. Soc. Heat. Vent. Eng., 52, 95-121.

Held, I. M., and B. J. Soden, 2000: Water vapor feedback and global warming. Annu. Rev. Energy Environ., 25, 441-475.

— , and — 2006: Robust responses of the hydrological cycle to global warming. J. Climate, 19, 5686-5699.

Ingram, W. J., 2002: On the robustness of the water vapor feedback: GCM vertical resolution and formulation. J. Climate, 15, 917-921.

Ishii, M., A. Shouji, S. Sugimoto, and T. Matsumoto, 2005: Objective analyses of sea-surface temperature and marine meteorological variables for the 20th century using ICOADS and the Kobe Collection. Int. J. Climatol., 25, 865-879.

Jensen, M. E., R. D. Burman, and R. G. Allen, Eds., 1990: Evapotranspiration and Irrigation Water Requirements: A Manual. American Society of Civil Engineers, 332 pp.

Jones, P. D., and A. Moberg, 2003: Hemispheric and large-scale surface air temperature variations: An extensive revision and an update to 2001. J. Climate, 16, 206-223.

—, M. New, D. E. Parker, S. Martin, and I. G. Rigor, 1999: Surface air temperature and its changes over the past 150 years. Rev. Geophys., 37, 173-199.

Kaiser, D. P., 2000: Decreasing cloudiness over China: An updated analysis examining additional variables. Geophys. Res. Lett., 27, 2193-2196.

Kalnay, E., and Coauthors, 1996: The NCEP/NCAR 40-Year Reanalysis Project. Bull. Amer. Meteor. Soc., 77, 437-471.

Karl, T. R., S. J. Hassol, C. D. Miller, and W. L. Murray, Eds., 2006: Temperature trends in the lower atmosphere: Steps for understanding and reconciling differences. Climate Change Science Program and Subcommittee on Global Change Research Rep., 218 pp.

Kent, E. C., and P. K. Taylor, 1996: Accuracy of humidity measurement on ships: Consideration of solar radiation effects. J. Atmos. Oceanic Technol., 13, 1317-1321.

$\longrightarrow$, R. J. Tiddy, and P. K. Taylor, 1993: Correction of marine air temperature observations for solar radiation effects. $J$. Atmos. Oceanic Technol., 10, 900-906.

— , P. G. Challenor, and P. K. Taylor, 1999: A statistical determination of the random observational errors present in voluntary observing ships meteorological reports. J. Atmos. Oceanic Technol., 16, 905-914.
Kiehl, J. T., and K. E. Trenberth, 1997: Earth's annual global mean energy budget. Bull. Amer. Meteor. Soc., 78, 197-208.

Lanzante, J. R., 1996: Resistant, robust and non-parametric techniques for the analysis of climate data: Theory and examples, including applications to historical radiosonde station data. Int. J. Climatol., 16, 1197-1226.

Lott, N., R. Baldwin, and P. Jones, 2001: The FCC integrated surface hourly database, a new resource of global climate data. National Climatic Data Center Tech. Rep. 2001-01, 42 pp.

Manabe, S., and R. T. Wetherald, 1967: Thermal equilibrium of atmosphere with a given distribution of relative humidity. $J$. Atmos. Sci., 24, 241.

- , and - 1975: The effects of doubling the $\mathrm{CO}_{2}$ concentration on the climate of a general circulation model. J. Atmos. Sci., 32, 3-15.

New, M., M. Hulme, and P. Jones, 2000: Representing twentiethcentury space-time climate variability. Part II: Development of 1901-96 monthly grids of terrestrial surface climate. J. Climate, 13, 2217-2238.

Pall, P., M. R. Allen, and D. A. Stone, 2007: Testing the ClausiusClapeyron constraint on changes in extreme precipitation under $\mathrm{CO}_{2}$ warming. Climate Dyn., 28, 351-363.

Parker, D. E., C. K. Folland, and M. Jackson, 1995: Marine surface temperature: Observed variations and data requirements. Climatic Change, 31, 559-600.

Peixoto, J. P., and A. H. Oort, 1996: The climatology of relative humidity in the atmosphere. J. Climate, 9, 3443-3463.

Press, W. H., S. A. Teukolsky, W. T. Vetterling, and B. P. Flannery, 1992: Numerical Recipes in C: The Art of Scientific Computing. 2nd ed. Cambridge University Press, 994 pp.

Rayner, N. A., D. E. Parker, E. B. Horton, C. K. Folland, L. V. Alexander, D. P. Rowell, E. C. Kent, and A. Kaplan, 2003: Global analyses of sea surface temperature, sea ice, and night marine air temperature since the late nineteenth century. J. Geophys. Res., 108, 4407, doi:10.1029/2002JD002670.

—, P. Brohan, D. E. Parker, C. K. Folland, J. J. Kennedy, M. Vanicek, T. Ansell, and S. F. B. Tett, 2006: Improved analyses of changes and uncertainties in sea surface temperature measured in situ since the mid-nineteenth century: The HadSST2 dataset. J. Climate, 19, 446-469.

Robinson, P. J., 2000: Temporal trends in United States dew point temperatures. Int. J. Climatol., 20, 985-1002.

Schönwiese, C. D., and J. Rapp, 1997: Climate Trend Atlas of Europe Based on Observations 1891-1990. Kluwer Academic Publishers, $228 \mathrm{pp}$

,-- , T. Fuchs, and M. Denhard, 1994: Observed climate trends in Europe 1891-1990. Meteor. Z., 3, 22-28.

Souch, C., and C. S. B. Grimmond, 2004: Applied climatology: 'Heat waves.' Prog. Phys. Geogr., 28, 599-606.

Steadman, R. G., 1984: A universal scale of apparent temperature. J. Climate Appl. Meteor., 23, 1674-1687.

Sun, D., and I. M. Held, 1996: A comparison of modeled and observed relationships between interannual variations of water vapor and temperature. J. Climate, 9, 665-675.

Taylor, K. E., D. Williamson, and F. Zwiers, 2000: The sea surface temperature and sea-ice concentration boundary conditions for AMIP II simulations. PCMDI Rep. 60, 25 pp.

Thorne, P. W., D. E. Parker, S. F. B. Tett, P. D. Jones, M. McCarthy, H. Coleman, and P. Brohan, 2005: Revisiting radiosonde upper air temperatures from 1958 to 2002. J. Geophys. Res., 110, D18105, doi:10.1029/2004JD005753. 
Trenberth, K. E., 1999a: Atmospheric moisture recycling: Role of advection and local evaporation. J. Climate, 12, 1368-1381.

_ 1999b: Conceptual framework for changes of extremes of the hydrological cycle with climate change. Climatic Change, 42, 327-339.

- 2005: Uncertainty in hurricanes and global warming. Science, 308, 1753-1754.

_ J. Fasullo, and L. Smith, 2005: Trends and variability in column-integrated atmospheric water vapor. Climate Dyn., 24, 741-758.

van Wijngaarden, W. A., and L. A. Vincent, 2005: Examination of discontinuities in hourly surface relative humidity in Canada during 1953-2003. J. Geophys. Res., 110, D22102, doi:10.1029/ 2005JD005925.

Vincent, L. A., X. Zhang, B. R. Bonsal, and W. D. Hogg, 2002: Homogenization of daily temperatures over Canada. J. Climate, 15, 1322-1334.

- W. A. van Wijngaarden, and R. Hopkinson, 2007: Temperature and humidity trends in Canada for 1953-2005. J. Climate, 20, 5100-5113.

Wang, J. X. L., and D. J. Gaffen, 2001: Late-twentieth-century climatology and trends of surface humidity and temperature in China. J. Climate, 14, 2833-2845.

Webb, M. J., and Coauthors, 2006: On the contribution of local feedback mechanisms to the range of climate sensitivity in two GCM ensembles. Climate Dyn., 27, 17-38, doi:10.1007/ s00382-006-0111-2.

Wentz, F. J., L. Ricciardulli, K. Hilburn, and C. Mears, 2007: How much more rain will global warming bring? Science, $\mathbf{3 1 7}, 233$ 235.

Willett, K. M., 2007: Creation and analysis of HadCRUH: A new global surface humidity dataset. Climatic Research Unit, School of Environmental Sciences, University of East Anglia, 174 pp.

- N. P. Gillett, P. D. Jones, and P. W. Thorne, 2007: Attribution of observed surface humidity changes to anthropogenic influence. Nature, 449, 710-712.

Worley, S. J., S. D. Woodruff, R. W. Reynolds, S. J. Lubker, and N. Lott, 2005: ICOADS release 2.1 data and products. Int. J. Climatol., 25, 823-842.

Zhang, T., and D. Sun, 2006: Response of water vapor and clouds to El Niño warning in three National Center for Atmospheric Research atmospheric models. J. Geophys. Res., 111, D17103, doi:10.1029/2005JD006700.

Zhang, X., F. W. Zwiers, G. C. Hegerl, F. H. Lambert, N. P. Gillett, S. Solomon, P. A. Stott, and T. Nozawa, 2007: Detection of human influence on twentieth-century precipitation trends. Nature, 448, 461-465. 